\title{
High-flow nasal cannula for acute hypoxemic respiratory failure in patients with COVID-19: systematic reviews of effectiveness and its risks of aerosolization, dispersion, and infection transmission
}

\section{Les canules nasales à haut débit pour le traitement de l'insuffisance respiratoire hypoxémique aiguë chez les patients atteints de la COVID-19: comptes rendus systématiques de l'efficacité et des risques d'aérosolisation, de dispersion et de transmission de l'infection}

\author{
Arnav Agarwal, MD $\cdot$ John Basmaji, MD $\cdot$ Fiona Muttalib, MD $\cdot$ David Granton, MD $\cdot$ \\ Dipayan Chaudhuri, MD $\cdot$ Devin Chetan, MD $\cdot$ Malini Hu, BSc $\cdot$ Shannon M. Fernando, MD · \\ Kimia Honarmand, MD · Layla Bakaa, OSSD • Sonia Brar, MD • Bram Rochwerg, MD • \\ Neill K. Adhikari, MD · Francois Lamontagne, MD • Srinivas Murthy, MD · David S. C. Hui, MD • \\ Charles Gomersall, MD · Samira Mubareka, MD · Janet V. Diaz, MD · Karen E. A. Burns, MD • \\ Rachel Couban, MISt $\cdot$ Quazi Ibrahim, MSc $\cdot$ Gordon H. Guyatt, MD $\cdot$ Per O. Vandvik, MD (1)
}

Received: 14 May 2020/Revised: 20 May 2020/Accepted: 20 May 2020/Published online: 15 June 2020

(C) Canadian Anesthesiologists' Society 2020

\begin{abstract}
Purpose We conducted two World Health Organizationcommissioned reviews to inform use of high-flow nasal cannula (HFNC) in patients with coronavirus disease (COVID-19). We synthesized the evidence regarding efficacy and safety (review 1), as well as risks of droplet dispersion, aerosol generation, and associated transmission (review 2) of viral products.
\end{abstract}

\footnotetext{
A. Agarwal, MD

Department of Medicine, University of Toronto, Toronto, ON, Canada

J. Basmaji, MD

Division of Critical Care, Department of Medicine, Schulich

School of Medicine and Dentistry, Western University, London,

ON, Canada

F. Muttalib, MD

Centre for Global Child Health, Hospital for Sick Children,

Toronto, ON, Canada

D. Granton, MD $\cdot$ M. Hu, BSc

Michael G. DeGroote School of Medicine, McMaster University,

Hamilton, ON, Canada
}

Source Literature searches were performed in Ovid MEDLINE, Embase, Web of Science, Chinese databases, and medRxiv. Review 1: we synthesized results from randomized-controlled trials (RCTs) comparing HFNC to conventional oxygen therapy (COT) in critically ill patients with acute hypoxemic respiratory failure. Review 2: we narratively summarized findings from studies evaluating droplet dispersion, aerosol generation, or infection transmission associated with HFNC. For both reviews,

D. Chaudhuri, MD

Department of Medicine, McMaster University, Hamilton, ON, Canada

D. Chetan, MD

Department of Pediatrics, University of Toronto, Toronto, ON, Canada

Division of Cardiology, Labatt Family Heart Centre, The Hospital for Sick Children, Toronto, ON, Canada

S. M. Fernando, MD

Division of Critical Care, Department of Medicine, University of Ottawa, Ottawa, ON, Canada

Department of Emergency Medicine, University of Ottawa, Ottawa, ON, Canada 
paired reviewers independently conducted screening, data extraction, and risk of bias assessment. We evaluated certainty of evidence using GRADE methodology.

Principal findings No eligible studies included COVID-19 patients. Review 1: 12 RCTs ( $n=1,989$ patients) provided low-certainty evidence that HFNC may reduce invasive ventilation (relative risk [RR], 0.85; $95 \%$ confidence interval [CI], 0.74 to 0.99) and escalation of oxygen therapy $(R R, 0.71 ; 95 \% C I, 0.51$ to 0.98$)$ in patients with respiratory failure. Results provided no support for differences in mortality (moderate certainty), or inhospital or intensive care length of stay (moderate and low certainty, respectively). Review 2: four studies evaluating droplet dispersion and three evaluating aerosol generation and dispersion provided very low certainty evidence. Two simulation studies and a crossover study showed mixed findings regarding the effect of HFNC on droplet dispersion. Although two simulation studies reported no associated increase in aerosol dispersion, one reported that higher flow rates were associated with increased regions of aerosol density. Conclusions High-flow nasal cannula may reduce the need for invasive ventilation and escalation of therapy compared with COT in COVID-19 patients with acute hypoxemic respiratory failure. This benefit must be balanced against the unknown risk of airborne transmission.

\section{Résumé}

Objectif Nous avons réalisé deux comptes rendus sur commande de l'Organisation mondiale de la santé pour guider l'utilisation de canules nasales à haut débit (CNHD) chez les patients ayant contracté le coronavirus

\section{K. Honarmand, MD}

Division of Critical Care, Department of Medicine, Schulich School of Medicine and Dentistry, Western University, London, ON, Canada

Schulich School of Medicine and Dentistry, Department of Medicine, Western University, London, ON, Canada

L. Bakaa, OSSD

Honours Life Sciences Program, Faculty of Science, McMaster University, Hamilton, ON, Canada

S. Brar, MD

School of Medicine and Biomedical Sciences, University of Buffalo, Buffalo, NY, USA

B. Rochwerg, MD

Michael G. DeGroote School of Medicine, McMaster University, Hamilton, ON, Canada

Department of Medicine, McMaster University, Hamilton, ON, Canada
(COVID-19). Nous avons synthétisé les données probantes concernant leur efficacité et leur innocuité (compte rendu 1), ainsi que les risques de dispersion des gouttelettes, de génération d'aérosols, et de transmission associée d'éléments viraux (compte rendu 2).

Source Des recherches de littérature ont été réalisées dans les bases de données Ovid MEDLINE, Embase, Web of Science, ainsi que dans les bases de données chinoises et medRxiv. Compte rendu 1: nous avons synthétisé les résultats d'études randomisées contrôlées (ERC) comparant les CNHD à une oxygénothérapie conventionnelle chez des patients en état critique atteints d'insuffisance respiratoire hypoxémique aiguë. Compte rendu 2: nous avons résumé sous forme narrative les constatations d'études évaluant la dispersion de gouttelettes, la génération d'aérosols ou la transmission infectieuse associées aux CNHD. Pour les deux comptes rendus, des réviseurs appariés ont réalisé la sélection des études, l'extraction des données et l'évaluation du risque de biais de manière indépendante. Nous avons évalué la certitude des données probantes en nous fondant sur la méthodologie GRADE.

Constatations principales Aucune étude éligible n'incluait de patients atteints de COVID-19. Compte rendu 1 : 12 ERC ( $n=1989$ patients) ont fourni des données probantes de certitude faible selon lesquelles les CNHD réduiraient la ventilation invasive (risque relatif [RR], 0,85; intervalle de confiance [IC] $95 \%, 0,74$ à 0,99) et l'intensification de l'oxygénothérapie (RR, 0,71; IC 95 $\%$, 0,51 à 0,98) chez les patients atteints d'insuffisance respiratoire. Les résultats n'ont pas démontré de différences en matière de mortalité (certitude modérée), ni de durée du séjour hospitalier ou à l'unité des soins intensifs (certitude modérée et faible, respectivement).

Department of Health Research Methods, Evidence and Impact, McMaster University, Hamilton, ON, Canada

N. K. Adhikari, MD

Department of Critical Care Medicine, Sunnybrook Health

Sciences Centre, Toronto, ON, Canada

Interdepartmental Division of Critical Care Medicine, University of Toronto, Toronto, ON, Canada

F. Lamontagne, MD

Université de Sherbrooke, Sherbrooke, Canada

Centre de recherche du CHU de Sherbrooke, Sherbrooke, QC, Canada

S. Murthy, MD

BC Children's Hospital, University of British Columbia, Vancouver, BC, Canada 
Compte rendu 2 : quatre études évaluant la dispersion de gouttelettes et trois évaluant la génération et la dispersion d'aérosols ont fourni des données probantes de très faible certitude. Deux études de simulation et une étude croisée ont donné des résultats mitigés quant à l'effet des CNHD sur la dispersion des gouttelettes. Bien que deux études de simulation n'aient rapporté aucune augmentation associée concernant la dispersion d'aérosols, l'une a rapporté que des taux de débit plus élevés étaient associés à des régions à densité d'aérosols élevée plus grandes.

Conclusion Les canules nasales à haut débit pourraient réduire la nécessité de recourir à la ventilation invasive et l'escalade des traitements par rapport à l'oxygénothérapie conventionnelle chez les patients atteints de COVID-19 souffrant d'insuffisance respiratoire hypoxémique aiguë. Cet avantage doit être soupesé contre le risque inconnu de transmission atmosphérique.

Keywords respiratory failure - COVID-19 .

SARS-CoV-2 $\cdot$ high-flow nasal cannula $\cdot$ aerosols

In December 2019, investigators identified a novel coronavirus, subsequently named by the World Health Organization (WHO) as severe acute respiratory syndrome coronavirus 2 (SARS-CoV-2), as the cause of atypical pneumonia cases in Wuhan, China. ${ }^{1}$ Since then, the disease caused by SARS-CoV-2 (named COVID-19) has emerged as a global pandemic. ${ }^{2}$ As of 15 May, SARS-CoV-2 has infected $>4$ million people in across 200 countries and has caused more than 290,000 deaths, the majority of which have occurred outside China. ${ }^{3}$ Although most patients

D. S. C. Hui, MD

Department of Medicine and Therapeutics, The Chinese

University of Hong Kong, Shatin, Hong Kong, SAR, China

Stanley Ho, Center for Emerging Infectious Diseases, The Chinese University of Hong Kong, Shatin, Hong Kong, SAR, China

C. Gomersall, MD

Department of Anaesthesia and Intensive Care, The Chinese

University of Hong Kong, Hong Kong, China

S. Mubareka, MD

Division of Infectious Diseases, Sunnybrook Health Sciences

Centre, Toronto, ON, Canada

Department of Laboratory Medicine and Pathobiology,

University of Toronto, Toronto, ON, Canada

J. V. Diaz, MD

Pacific Medical Center, San Francisco, CA, USA

World Health Organization, Geneva, Switzerland present with mild respiratory symptoms, some have severe pneumonia and a small proportion become critically ill., The volume of severe cases has created an unprecedented burden on healthcare systems, highlighting the urgency in identifying safe, effective therapies for COVID-19.

Severe COVID-19 often progresses to acute hypoxemic respiratory failure requiring high fractional concentration of inspired oxygen $\left(\mathrm{F}_{\mathrm{I}} \mathrm{O}_{2}\right)$ and consideration for noninvasive ventilation (NIV) strategies. ${ }^{6-9}$ High-flow nasal cannula has emerged as a non-invasive strategy improving oxygenation and carbon dioxide clearance by, relative to other NIV strategies, better matching of patients' inspiratory demands by delivering up to $60 \mathrm{~L} \cdot \mathrm{min}^{-1}$ of gas flow with an $\mathrm{F}_{\mathrm{I}} \mathrm{O}_{2}$ up to 1.0, and thus decreasing adverse outcomes. ${ }^{10-14} \mathrm{~A}$ recent systematic review found low certainty evidence for a benefit of HFNC in reducing the need for invasive ventilation or escalation of oxygen therapy compared with conventional oxygen therapy (COT), and moderate certainty evidence suggesting no large difference in mortality. ${ }^{15}$ Nevertheless, HFNC may reduce the need for invasive ventilation and associated adverse events such as ventilator-associated pneumonias, and also alleviate the strain on healthcare systems during the COVID-19 pandemic.

COVID-19 spreads through respiratory droplets and fomites. ${ }^{1,16,17}$ There is concern, however, that airborne transmission may occur during procedures that generate aerosols. ${ }^{17}$ Airborne transmission involves smaller particles (droplet nuclei), typically $<5 \mu \mathrm{m}$ in diameter, which may remain suspended in the air for extended periods of time, transmitted over distances greater than 1 $\mathrm{m}$, and inhaled into the lower airways. ${ }^{17}$ Reduction of

K. E. A. Burns, MD

Unity Health Toronto - St. Michael's Hospital, Toronto, ON, Canada

University of Toronto, Toronto, ON, Canada

Li Ka Shing Knowledge Institute, Toronto, ON, Canada

R. Couban, MISt

Department of Health Research Methods, Evidence and Impact, McMaster University, Hamilton, ON, Canada

Michael G. DeGroote Institute for Pain Research and Care, McMaster University, Hamilton, ON, Canada

Q. Ibrahim, MSc · G. H. Guyatt, MD

Department of Health Research Methods, Evidence and Impact, McMaster University, Hamilton, ON, Canada

P. O. Vandvik, MD ( $\square)$

MAGIC Evidence Ecosystem Foundation, Oslo, Norway

e-mail: per.vandvik@gmail.com 
respiratory particles to $<5 \mu \mathrm{m}$ involves dehydration of larger droplets and their contained organisms, and rehydration after deposition into the airway; therefore, airborne transmission is organism-specific, and requires the organism to survive a process of desiccation and aerosolization in sufficient numbers to cause infection. ${ }^{18}$

On 29 March 2020, the WHO issued a scientific brief recommending droplet and contact precautions for the care of COVID-19 patients and airborne precautions during aerosol-generating procedures. ${ }^{17}$ The use of high flow rates raises concerns that HFNC may cause aerosolization of infectious particles. The Surviving Sepsis Campaign COVID-19 guidelines provide a weak recommendation for the preferential use of HFNC over other NIV strategies in patients refractory to COT. ${ }^{19}$ Nevertheless, the guidelines did not consider how different circumstances may change the balance between risks and benefits of HFNC, and considered only two studies in evaluating risk of disease transmission. ${ }^{20}$

The severe resource constraints in healthcare settings facing large numbers of COVID-19 patients dictates an urgent need for an updated evidence synthesis and guidance regarding the use of HFNC among these patients. We conducted two rapid systematic reviews commissioned by the WHO to summarize the evidence for the efficacy, safety, and risk of aerosol generation and infection transmission during HFNC use among patients with acute hypoxemic respiratory failure due to COVID19.

\section{Methods}

Prior to beginning, WHO personnel reviewed and approved internal protocols for both systematic reviews; given time constraints of the commissioned reviews (seven days to completion), neither protocol was registered nor published.

Systematic review \#1: efficacy and safety of HFNC in acute hypoxemic respiratory failure

\section{Literature search}

A previous systematic review searched Ovid MEDLINE, Embase, and Web of Science for eligible randomizedcontrolled trials (RCTs) from 1 January 2007 to 25 October 2018. ${ }^{15}$ With input from a health information specialist, we updated this systematic review, searching Ovid MEDLINE, Embase, and Web of Science from 1 October 2018 to 14 May 2020 with no language restrictions (see Appendix 1).

\section{Selection criteria}

We included RCTs that compared HFNC with COT in critically ill patients with acute hypoxemic respiratory failure. We defined COT as inhaled oxygen via nasal prongs, simple face masks, face masks with reservoir bags, or Venturi masks. Eligible studies reported one or more of the following pre-specified outcomes: mortality (using the longest follow-up available), invasive ventilation, escalation of therapy (crossover to HFNC in the control group, or initiation of NIV or invasive ventilation in either group), intensive care unit (ICU) and hospital lengths of stay (LOS), patient-reported comfort and dyspnea, and treatment-related complications.

To identify potential additional eligible RCTs, we reviewed relevant systematic reviews. We excluded case reports, case series, and observational studies as well as studies that (i) used NIV or invasive ventilation as a sole comparator with no COT arm, (ii) evaluated the role of HFNC peri-intubation, or (iii) evaluated the role of HFNC for post-extubation respiratory support. These exclusions aligned with the most common indication for HFNC-i.e., as an alternative to COT in a patient with hypoxemic respiratory failure not requiring immediate intubation.

\section{Study selection}

Paired reviewers (D.C.1, D.G., M.H., D.C.2) screened the title and abstract of identified citations, followed by fulltext review of potentially eligible studies. A third reviewer (A.A.) resolved disagreements. We captured reasons for exclusion at the full-text review stage. Single reviewers (D.C.1, M.H., D.G.) screened the reference lists of relevant systematic reviews to identify additional RCTs meeting eligibility criteria.

\section{Data extraction and quality assessment}

Paired reviewers (D.G., D.C.2) performed data extraction independently and in duplicate using pre-designed forms consistent with those used for the original review. We abstracted data regarding study characteristics, demographic data, intervention and control details, outcome data, and risk of bias (RoB) evaluations using the modified Cochrane RoB tool. ${ }^{21}$ A third reviewer (A.A.) resolved disagreements.

Risk of bias was classified as "low", "probably low", "probably high", or "high" for the following domains: sequence generation, allocation sequence concealment, blinding, selective outcome reporting, and other bias. We rated the overall $\mathrm{RoB}$ as the highest risk attributed to any criterion. We rated the overall certainty in evidence for each outcome using the GRADE framework, ${ }^{22}$ including 
the following domains: RoB, imprecision, inconsistency, indirectness, and publication bias. Overall certainty of evidence was "very low", "low", "moderate", or "high". We considered rating down the certainty of evidence for RoB based on lack of blinding for subjective outcomes. Certainty in evidence was not rated down for indirectness if patients with acute hypoxemic respiratory failure meeting eligibility criteria other than SARS-CoV-2 infection were included. Assessors resolved disagreements regarding RoB and GRADE ratings by discussion.

\section{Data analysis}

DerSimonian and Laird random effects models were used to conduct the meta-analyses. All analyses were performed in RevMan 5.3 (Cochrane Collaboration, Oxford). Study weights were generated using the inverse variance method. Dichotomous outcomes were presented as risk ratios, and continuous outcomes were presented as mean differences or standardized mean differences, all with $95 \%$ confidence intervals (CIs). We assumed a normal distribution for continuous outcomes and converted interquartile ranges to standard deviations (SD) as per Cochrane Collaboration guidance. ${ }^{23}$ An online plot digitizer was used to obtain estimates for studies in which continuous outcomes were reported graphically only (plotdigitizer.sourceforge.net).

We assessed for heterogeneity between studies using the $\chi 2$ test for homogeneity, the $\mathrm{I}^{2}$ measure, and visual inspection of the forest plots. $^{23} \mathrm{We}$ evaluated inconsistency based on magnitude and direction of heterogeneity. Based on limited yield of numerous subgroup analyses performed in the previous systematic review, we restricted subgroup analysis to high RoB studies $v s$ low RoB studies (hypothesizing that HFNC would be more beneficial in high RoB studies).

Systematic review \#2: risk of aerosol generation associated with HFNC

\section{Literature search}

With the assistance of a health information specialist (R.C.) and using a combination of subject headings and keywords related to COVID-19, other coronaviruses, and HFNC, we conducted a comprehensive search of Ovid MEDLINE and Embase from inception to 14 May 2020. We supplemented this with a search in the same databases using a combination of subject headings and keywords related to HFNC, aerosol generation, and infection transmission. We did not limit the search to COVID-19 or coronavirus infections (see Appendix 2). We limited the search to literature published between 1 January 2007 and 14 May 2020. To identify Chinese studies or rapid reviews addressing the research question, we also searched the China National Knowledge Infrastructure (CNKI) and Chinese Medical Journal Network (CMJN) using the same search strategy up to 28 March 2020. To identify eligible pre-prints, we searched medRxiv from inception to 14 May 2020 with search terms related to HFNC, aerosol generation, and droplet dispersion. We did not apply any language or quality restrictions.

\section{Selection criteria}

We included all comparative and non-comparative studies that evaluated droplet dispersion or aerosolization of viable airborne organisms or transmission of infection associated with HFNC use. Anticipating the paucity of direct evidence from COVID-19 and hospitalized patients, we included all study designs and populations evaluating aerosol generation or dispersion associated with HFNC. We included studies of hospitalized and non-hospitalized patients with or without microbiologically confirmed SARS-CoV-2 infection, simulation studies without human participants, and studies describing dispersion of noninfectious air particles or liquid droplets. We included studies that evaluated the following outcomes: detection of droplets or viable airborne organisms through sample analysis, or documented transmission of infection associated with exposure to infected individuals receiving HFNC, with or without comparison with an alternate ventilation modality.

\section{Study selection}

Paired reviewers (J.B., F.M.) screened all identified citations, conducted full-text review of potentially eligible studies and screened the reference lists of reviews to identify additional eligible studies. A third reviewer (A.A.) resolved disagreements. Paired reviewers (X.Y., N.Y., X.L.) screened citations identified from the CNKI and CMJN and resolved disagreements by discussion.

\section{Data extraction and quality assessment}

Paired reviewers (J.B., F.M.) abstracted data (study characteristics, participant characteristics, description of the intervention and control, outcomes, and general limitations in study design and conduct) independently and in duplicate using standardized data abstraction forms. A third reviewer (A.A.) resolved disagreements as necessary.

Informed by GRADE guidance, we assessed the overall certainty of the evidence based on imprecision, indirectness, and inconsistency. ${ }^{24}$ 


\section{Data analysis}

Given anticipated differences in included study designs, we summarized our findings narratively.

\section{Results}

Systematic review \#1: efficacy and safety of HFNC in acute hypoxemic respiratory failure

\section{Search results and study characteristics}

Of the 2,439 citations identified in our search, 1,814 were screened for eligibility after removing duplicates. Full-text review of 38 potentially eligible studies identified 20 eligible studies. Of these, 17 were systematic reviews (SRs) ${ }^{15,25-40}$ and three were RCTs ${ }^{41-43}$ (Fig. 1). We did not identify additional RCTs from reference lists of eligible SRs. Therefore, 12 RCTs with 1,989 patients were included in analyses, including nine RCTs from the original review and three RCTs from the updated search. ${ }^{41-52}$ No trial directly evaluated HFNC in patients with COVID-19 or other coronavirus infections.

Table 1 summarizes study characteristics. Trials randomized between 14 and 776 patients; two used a crossover design. ${ }^{43,52}$ Five trials were performed in the ICU, ${ }^{45,46,48,50,52}$ six were performed in the emergency department (ED), ${ }^{42-44,47,49,51}$ and one was performed in mixed ICU/ED settings. ${ }^{41}$ One trial included patients with cardiogenic pulmonary edema only, ${ }^{44}$ two included immunocompromised patients only, ${ }^{45,46}$ and one included palliative patients only. ${ }^{43}$ Criteria for hypoxemia varied, including peripheral oxygen saturation $\left(\mathrm{SpO}_{2}\right)$ thresholds (primarily $<90-95 \%$ ), arterial partial pressure of oxygen $\left(\mathrm{PaO}_{2}\right)$ thresholds $(<55-60 \mathrm{mmHg}), \mathrm{P} / \mathrm{F}$ ratio $(<300)$, or a combination of criteria including elevated respiratory rate (most commonly $>22-25 / \mathrm{min}$ ). All eligible studies initiated gas flows at $35 \mathrm{~L} \cdot \mathrm{min}^{-1}$ or higher in the HFNC group with one exception ${ }^{42}$ that used initial flow rates of 19.5 to $30 \mathrm{~L} \cdot \mathrm{min}^{-1}$ (Table 1 ).

\section{Quality assessment}

No RCT was blinded. Most were judged to be at low RoB for random sequence generation, allocation concealment, incomplete data, selective reporting, and other sources of bias. Apart from blinding, seven ${ }^{41,43,44,46,48,50,52}$ of 12 included trials were deemed to be at low overall RoB (Table 2).

\section{Outcomes}

Table 3 presents the GRADE summary of findings for all pre-specified outcomes except treatment-related complications (summarized below), with anticipated effects of HFNC and evidence certainty when applied to patients with acute respiratory failure.

The use of HFNC may reduce the need for invasive ventilation compared with COT (eight RCTs; relative risk [RR], $0.85 ; 95 \% \mathrm{CI}, 0.74$ to 0.99 ; risk difference [RD], $4.4 \% ; 95 \% \mathrm{CI}, 0.3$ to 7.6 ; number needed to treat [NNT], 23; $95 \%$ CI, 13 to 333; low certainty, rated down for RoB and imprecision; $\mathrm{I}^{2}, 0 \%$ ) (Fig. 2). There was no credible subgroup effect comparing high vs low RoB studies (Fig. 2).

The use of HFNC may also reduce the need for escalation of therapy (i.e., other NIV or intubation) compared with COT (eight RCTs; RR, 0.71; 95\% CI, 0.51 to 0.98 ; RD, $9.3 \%$; $95 \% \mathrm{CI}, 0.6$ to 15.7 ; NNT, 11 ; $95 \%$ CI, 6 to 167; low certainty, rated down for RoB and imprecision; $\mathrm{I}^{2}, 52 \%$ ) (Fig. 2). There was no credible subgroup effect based on individual study RoB (Fig. 3). Results provided no support for differences in mortality (moderate certainty), in-hospital or intensive care LOS (moderate and low certainty, respectively), and patientreported dyspnea or comfort (low and very low certainty, respectively) (Table 3, Figs. 4, 5, 6, 7, 8).

Eligible studies reported treatment-related complications variably, precluding pooled analyses. Among reported complications with HFNC, thoracocervical discomfort, heat-related discomfort, and mild altered level of consciousness were most common. One trial reported serious complications, including cardiac dysrhythmias, septic shock, cardio-respiratory arrest, and nosocomial pneumonias; the incidence of these complications were either similar or lower than HFNC compared with COT. ${ }^{48}$ Studies generally did not suggest a significantly increased risk of complications with HFNC compared with COT (Table 4).

Systematic review \#2: risk of aerosol generation associated with HFNC

\section{Search results and study characteristics}

We identified 3,523 unique citations using our electronic searches, 26 pre-prints from medRxiv, and one additional citation suggested by an expert panelist. We completed full-text review of 33 potentially eligible studies and included six studies, ${ }^{53-58}$ and identified one additional study through reference list screening, ${ }^{59}$ for a total of seven eligible studies (Fig. 9). ${ }^{53-59}$ 

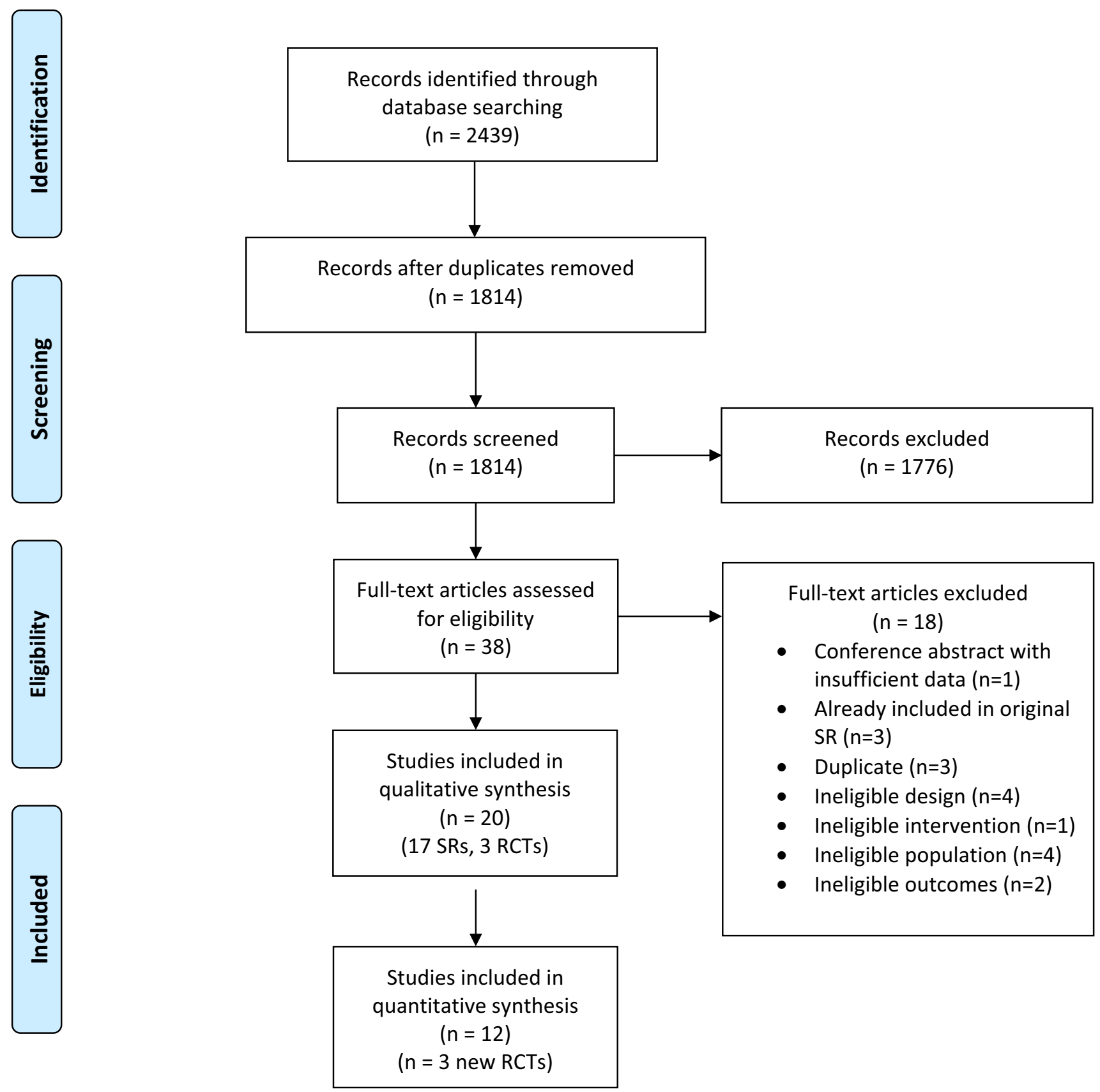

Fig. 1 PRISMA flow diagram for systematic review 1 on efficacy and safety of HFNC in acute hypoxemic respiratory failure. $\mathrm{SR}=$ systematicreviews; $\mathrm{RCT}=$ randomized-controlled trial

Of the seven eligible studies, six were simulation studies $^{53-55,57-59}$ and one was a crossover study. ${ }^{56}$ No studies directly evaluated risk of aerosol generation or infection transmission associated with HFNC use among patients with COVID-19. Three simulation studies included healthy adult volunteers, ${ }^{54,58,59}$ and three included a model patient simulator. ${ }^{53,55,57}$ The crossover study included 19 critically ill adult patients who received supplemental oxygen therapy and crossed over to HFNC. ${ }^{56}$ Three studies ${ }^{53,58,59}$ evaluated HFNC at $30 \mathrm{~L} \cdot \mathrm{min}^{-1}$, one evaluated $\mathrm{HFNC}$ at $40 \mathrm{~L} \cdot \mathrm{min}^{-1}, 57$ and six studies ${ }^{53-56,58,59}$ evaluated $\mathrm{HFNC}$ at $60 \mathrm{~L} \cdot \mathrm{min}^{-1}$. One study compared HFNC with continuous positive airway pressure (CPAP) delivering pressures of $5-20 \mathrm{cmH}_{2} \mathrm{O},{ }^{53}$ another compared HFNC with COT by face mask, ${ }^{56}$ two compared HFNC with COT by nasal prongs at $6 \mathrm{~L} \cdot \mathrm{min}^{-1,57,58}$ and one compared HFNC with non-rebreather mask with nonhumidified air at $15 \mathrm{~L} \cdot \mathrm{min}^{-1} .^{58}$ The remaining three studies $^{54,55,59}$ did not include an alternative oxygen administration or ventilatory support strategy as a 


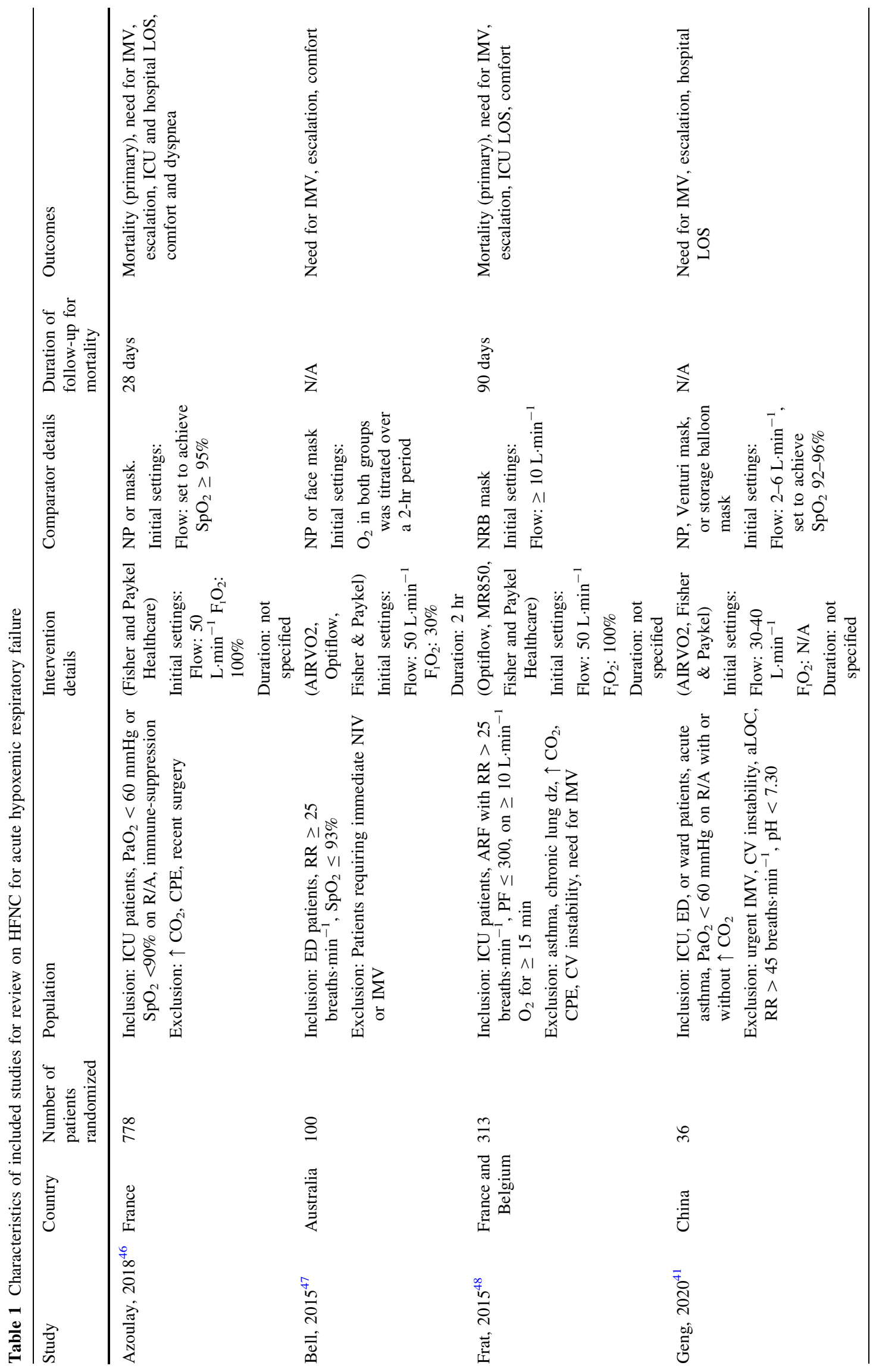




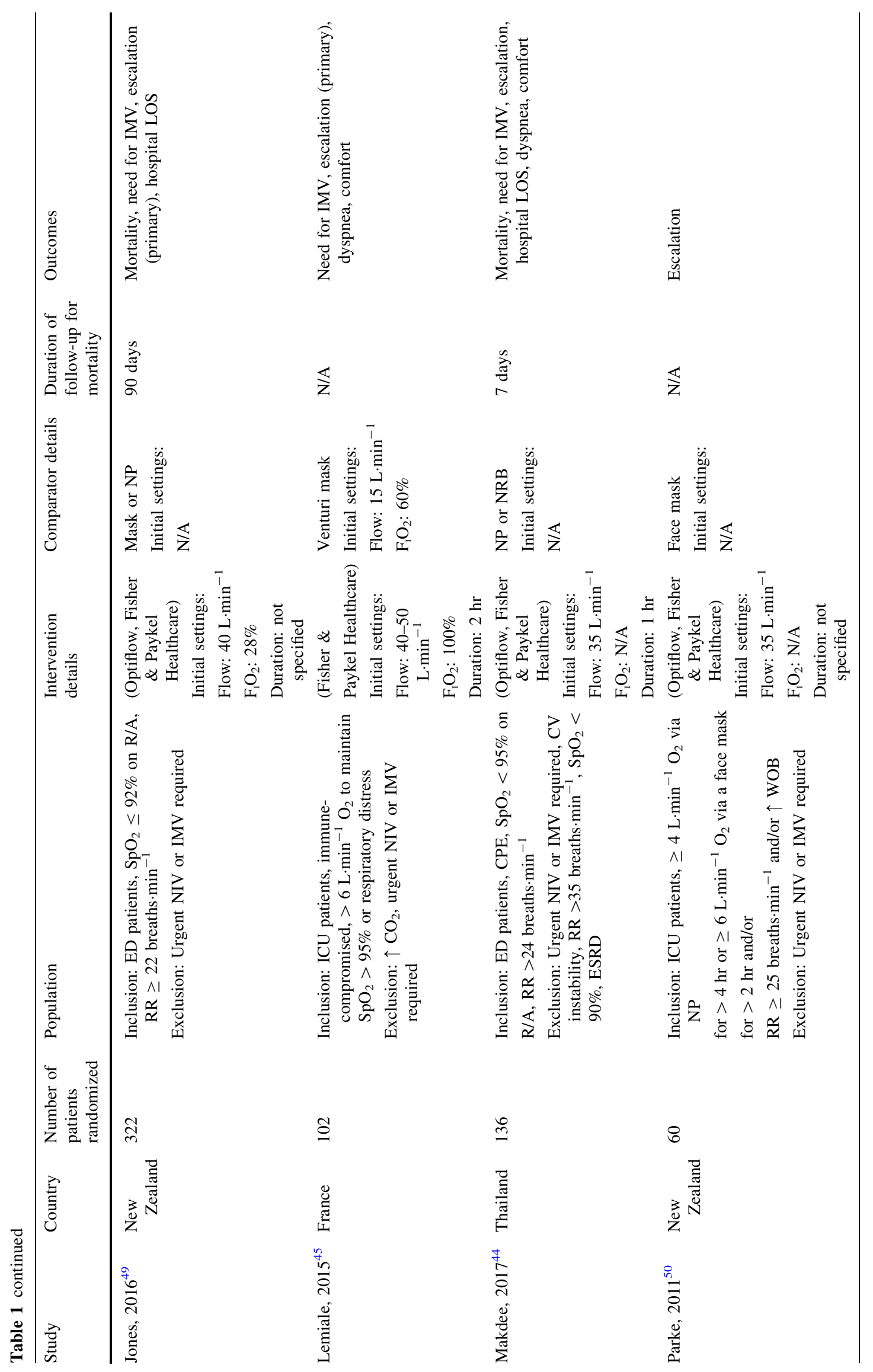




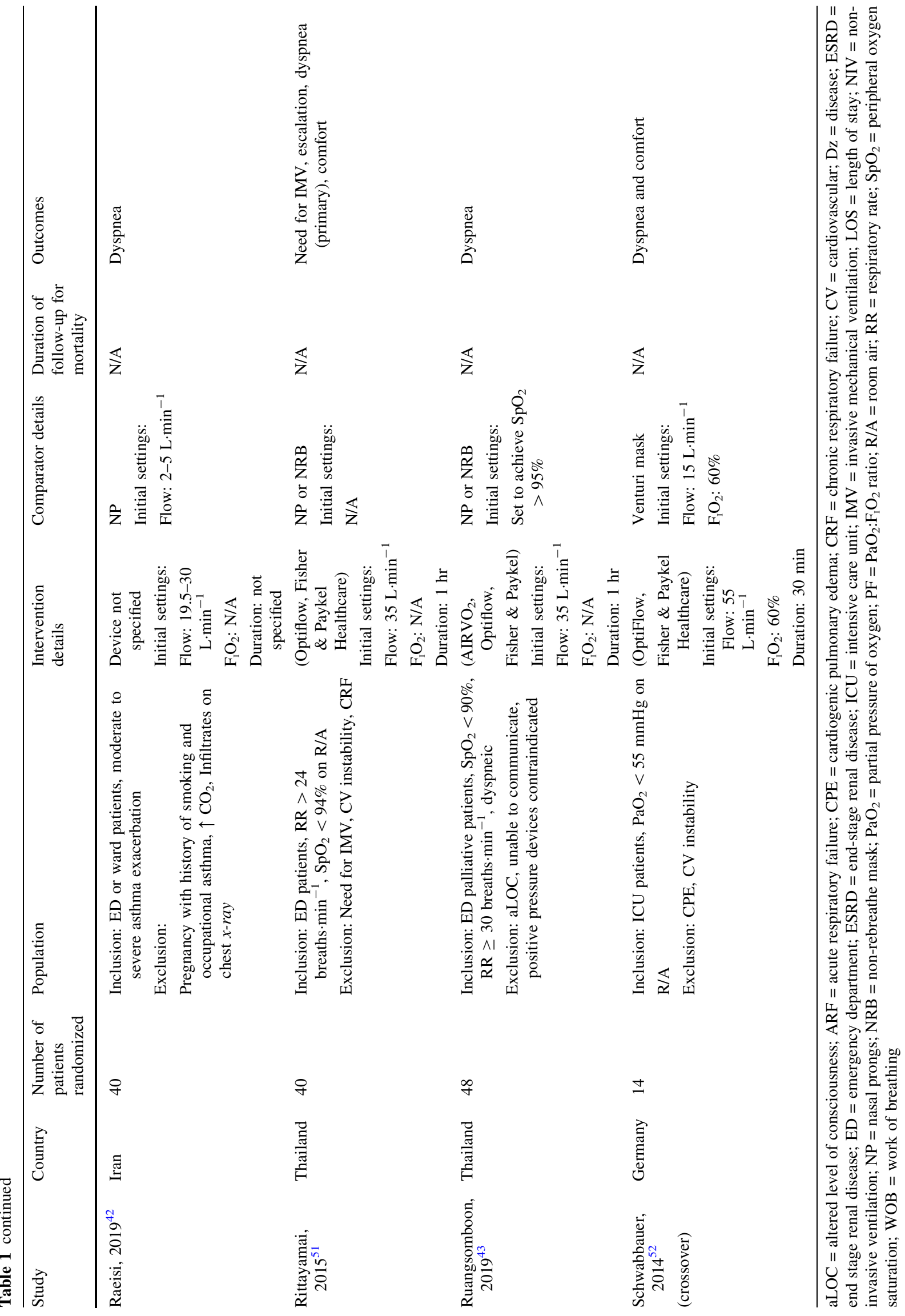


Table 2 Individual study risk of bias for review on HFNC for acute hypoxemic respiratory failure

\begin{tabular}{|c|c|c|c|c|c|c|c|}
\hline & $\begin{array}{l}\text { Random sequence } \\
\text { generation }\end{array}$ & $\begin{array}{l}\text { Allocation } \\
\text { concealment }\end{array}$ & Blinding & $\begin{array}{l}\text { Incomplete outcome } \\
\text { data }\end{array}$ & $\begin{array}{l}\text { Selective } \\
\text { reporting }\end{array}$ & Other bias & $\begin{array}{l}\text { Overall } \\
\text { RoB }\end{array}$ \\
\hline Azoulay, $2018^{46}$ & Low & Low & High & Low & Low & Low & Low \\
\hline Bell, $2015^{47}$ & Low & Low & High & High & Low & Low & High \\
\hline Frat, $2015^{48}$ & Low & Low & High & Low & Low & Low & Low \\
\hline Geng, $2020^{41}$ & Low & Low & High & Low & Low & Low & Low \\
\hline Jones, $2016^{49}$ & Low & Low & High & High & Low & Low & High \\
\hline Lemiale, $2015^{45}$ & Probably low & Low & High & Low & Probably high & Low & High \\
\hline Makdee, $2017^{44}$ & Probably low & Low & High & Low & Low & $\begin{array}{l}\text { Probably } \\
\text { low }\end{array}$ & Low \\
\hline Parke, $2011^{50}$ & Low & Low & High & Probably low & Probably low & Low & Low \\
\hline Raeisi, $2019^{42}$ & Probably low & Probably high & High & High & High & Low & High \\
\hline Rittayamai, $2015^{51}$ & Probably low & Low & High & High & Probably low & Low & High \\
\hline $\begin{array}{l}\text { Ruangsomboon, } \\
2019^{43}\end{array}$ & Low & Low & High & Probably low & Low & Low & Low \\
\hline $\begin{array}{l}\text { Schwabbauer, } \\
2014^{52}\end{array}$ & Probably low & Probably low & High & Probably low & Probably low & Low & Low \\
\hline
\end{tabular}

HFNC = high-flow nasal cannula; RoB $=$ risk of bias

comparator. Study outcomes included the number, diameter, evaporation rates, and velocity of exhaled aerosols ${ }^{58,59}$ regions of high aerosol density, ${ }^{53}$ droplet dispersion distance, ${ }^{54,55,57}$ and microbial colony counts in air and surface samples (Table 5). ${ }^{56}$

Study findings

\section{Exhaled aerosol dispersion}

Using a human patient simulator programmed to different severities of lung injury in a negative pressure room with $20+$ breathing cycles at every given flow rate, Hui et al. ${ }^{53}$ compared CPAP via nasal pillows and oronasal mask, delivering pressures between 5 and $20 \mathrm{cmH}_{2} \mathrm{O}$ to humidified HFNC with flow rates of 10,30 , and 60 $\mathrm{L} \cdot \mathrm{min}^{-1}$. Under normal lung conditions, increased HFNC flow rates were associated with a larger distance of high aerosol density (maximum dimension $6.5 \pm 1.5 \mathrm{~cm}$ at 10 $\mathrm{L} \cdot \mathrm{min}^{-1}$ to $17.2 \pm 3.3 \mathrm{~cm}$ at $\left.60 \mathrm{~L} \cdot \mathrm{min}^{-1} ; P<0.001\right)$. Similar, though smaller, increases were noted in simulated mild $\left(4.3 \pm 1.0 \mathrm{~cm}\right.$ at $10 \mathrm{~L} \cdot \mathrm{min}^{-1}$ to $7.2 \pm 1.8 \mathrm{~cm}$ at 60 $\left.\mathrm{L} \cdot \mathrm{min}^{-1}\right)$ and severe lung disease $(3.0 \pm 0.8 \mathrm{~cm}$ at 10 $\mathrm{L} \cdot \mathrm{min}^{-1}$ to $4.8 \pm 1.6 \mathrm{~cm}$ at $60 \mathrm{~L} \cdot \mathrm{min}^{-1}$ ). The region was not uniform, with negligible lateral extension with a wellfitted, well-positioned cannula, although the lateral distance with the cannula loosely positioned in the nose was $62 \mathrm{~cm}^{53}$

Roberts et al. ${ }^{59}$ conducted a simulation study including healthy adult volunteers. They compared dispersion of exhaled aerosols with and without nasal HFNC at 30 and
$60 \mathrm{~L} \cdot \mathrm{min}^{-1}$ during two "violent" (snorting) exhalations and at rest using imaging (number of simulations and imaging methods not described). During violent exhalation, there was less dispersion with HFNC than without, though flow rates of $60 \mathrm{~L} \cdot \mathrm{min}^{-1}$ were associated with greater dispersion than flow rates of $30 \mathrm{~L} \cdot \mathrm{min}^{-1}$. With and without HFNC, 25-250- $\mu \mathrm{m}$ aerosols travelled up to 4.4 $\mathrm{m}$ and remained airborne for up to $43 \mathrm{sec}$ (unclear if at rest or with violent exhalation). The authors concluded that HFNC did not increase the risk of aerosol dispersion more than typical patient breathing with violent exhalation. ${ }^{59}$

\section{Exhaled aerosol production}

Iwashyna et al. ${ }^{58}$ conducted a simulation study of four healthy adult volunteers. They evaluated variations in exhaled aerosol production with spontaneous breathing with intentional coughing, comparing $\mathrm{HFNC}$ at $30 \mathrm{~L} \cdot \mathrm{min}^{-1}$ and $60 \mathrm{~L} \cdot \mathrm{min}^{-1}$, nasal cannula at $6 \mathrm{~L} \cdot \mathrm{min}^{-1}$, and nonrebreather mask with non-humidified air at $15 \mathrm{~L} \cdot \mathrm{min}^{-1}$. The study was conducted in a simulated single occupancy hospital room with all equipment, monitors, and computers standard to this setting. Investigators wore standard surgical masks. Measurements were taken in two positions: $10 \mathrm{~cm}$ from the simulated patient's mouth, and attached to a bed rail next to the head. Similar aerosol production levels and particle number concentrations were found with both flow rates of HFNC compared with nasal prongs, non-rebreather mask, and spontaneous breathing. ${ }^{58}$ 


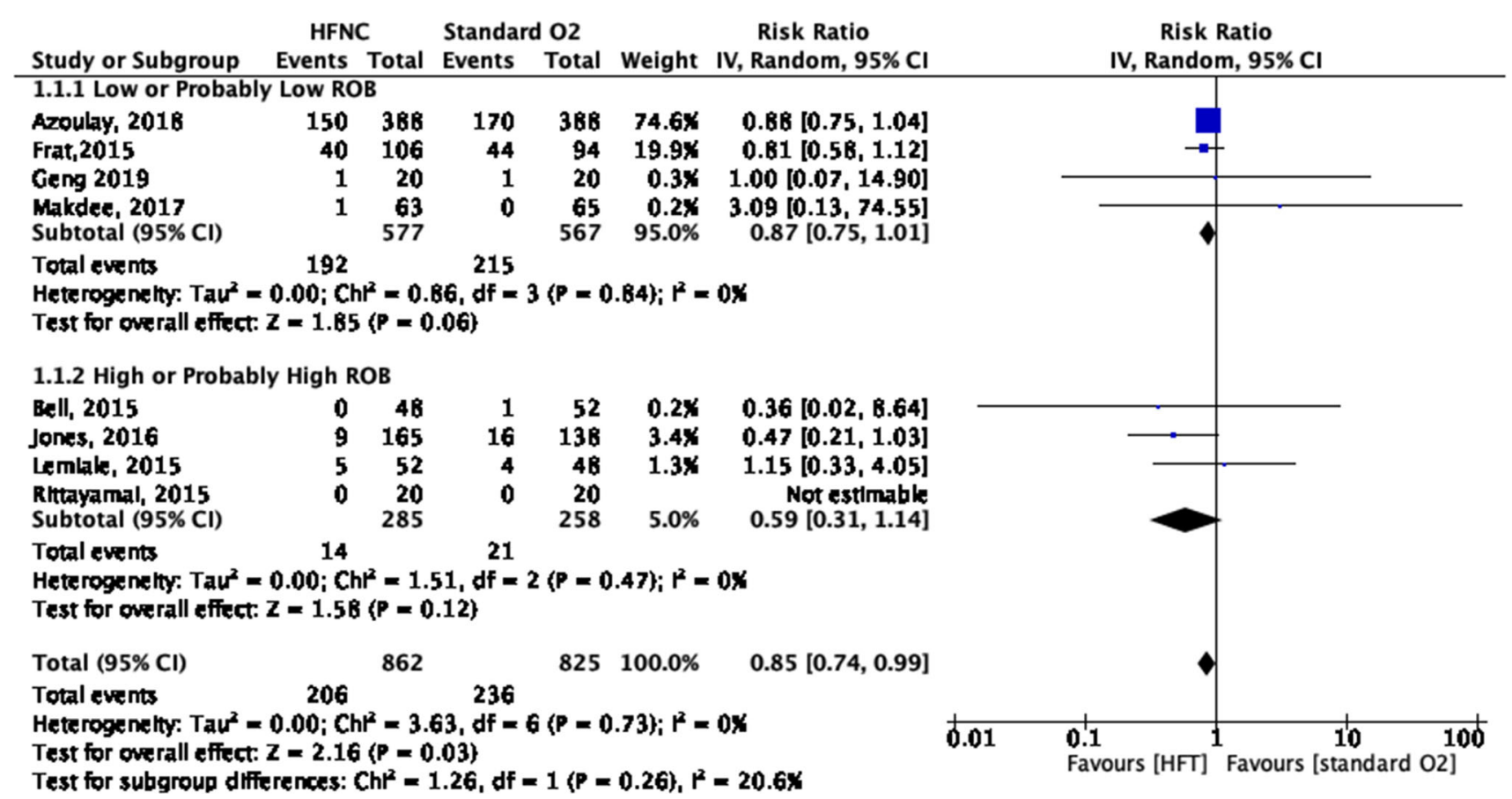

Fig. 2 Need for invasive ventilation forest plot for review on HFNC for acute hypoxemic respiratory failure. CI = confidence interval; HFNC = high-flow nasal cannula; $\mathrm{RoB}=$ risk of bias

\section{Exhaled droplet dispersion distance}

Loh et al. ${ }^{54}$ evaluated cough-generated droplet dispersion distance with two coughs per participant across five healthy volunteers, using gargled water containing coloured dye. The study found similar mean (SD) maximum coughgenerated droplet dispersion distances at baseline [248 (103) $\mathrm{cm}$ ] and with application of HFNC at $60 \mathrm{~L} \cdot \mathrm{min}^{-1}$ [291 (109) cm]. Highest cough-generated droplet dispersion distances with simulated coughs were $450 \mathrm{~cm}$ and $390 \mathrm{~cm}$ with and without application of HFNC, respectively. ${ }^{54}$

Kotoda et $a l^{55}$ evaluated thickened liquid dispersion distance with and without HFNC at $60 \mathrm{~L} \cdot \mathrm{min}^{-1}$ using an experimental mannequin model with three simulations using water. Water dispersion was detected using 18 sheets of water-sensitive paper positioned at $30 \mathrm{~cm}$ intervals. Water was only detected on the first sheet $(30 \mathrm{~cm})$ from the mannequin's face with a mean (SD) of 3.7 (1.2) spots. Manual repositioning of the cannula led to a statistically significant increase in liquid dispersion across the first three sheets $(P=0.0032){ }^{55}$

Leonard et al. ${ }^{57}$ conducted an in silico simulation using a three-dimensional head, comparing intentional mask leak, droplet capture by face mask, and dispersion from point of origin with $\mathrm{HFNC}$ at $40 \mathrm{~L} \cdot \mathrm{min}^{-1}$, nasal prongs at 6 $\mathrm{L} \cdot \mathrm{min}^{-1}$, and tidal breathing. A level-1 surgical mask was placed over the face for all interventions. The proportion of escaped particles while wearing a surgical face mask that travelled greater than $1 \mathrm{~m}$ were higher with HFNC (15.9\%) compared with nasal prongs $(6.9 \%)$, though lower than tidal breathing without a mask $(31 \%)$. There were significant reductions in exhaled gas flow velocities and particle dispersion with a surgical face mask in place, although there was both greater mask leak and droplet capture by face mask with HFNC compared with nasal prongs. In comparison, tidal breathing had lower mask leak and higher droplet capture. ${ }^{57}$

\section{Dispersion of viable organisms}

Kotoda et al. ${ }^{55}$ conducted three simulations using fresh yeast (Sacchromyces cerevisiae), evaluating dispersion with and without HFNC at $60 \mathrm{~L} \cdot \mathrm{min}^{-1}$ in an experimental mannequin model. Yeast dispersion was evaluated using 18 Petri dishes placed at $30-\mathrm{cm}$ intervals from the mannequin and four dishes placed $5 \mathrm{~m}$ away. Colonies were only detected in the closest dish with a mean (SD) of 2.3 (0.5) colony forming units, and there was increased dispersion extending to two dishes in front of and lateral to the mannequin with manual repositioning of the cannula $(P=0.039)$. The investigators did not observe colony formation on the dishes $5 \mathrm{~m}$ away from the mannequin. ${ }^{55}$

Leung et al. ${ }^{56}$ conducted a prospective study of 19 critically ill adults receiving COT because of gram- 


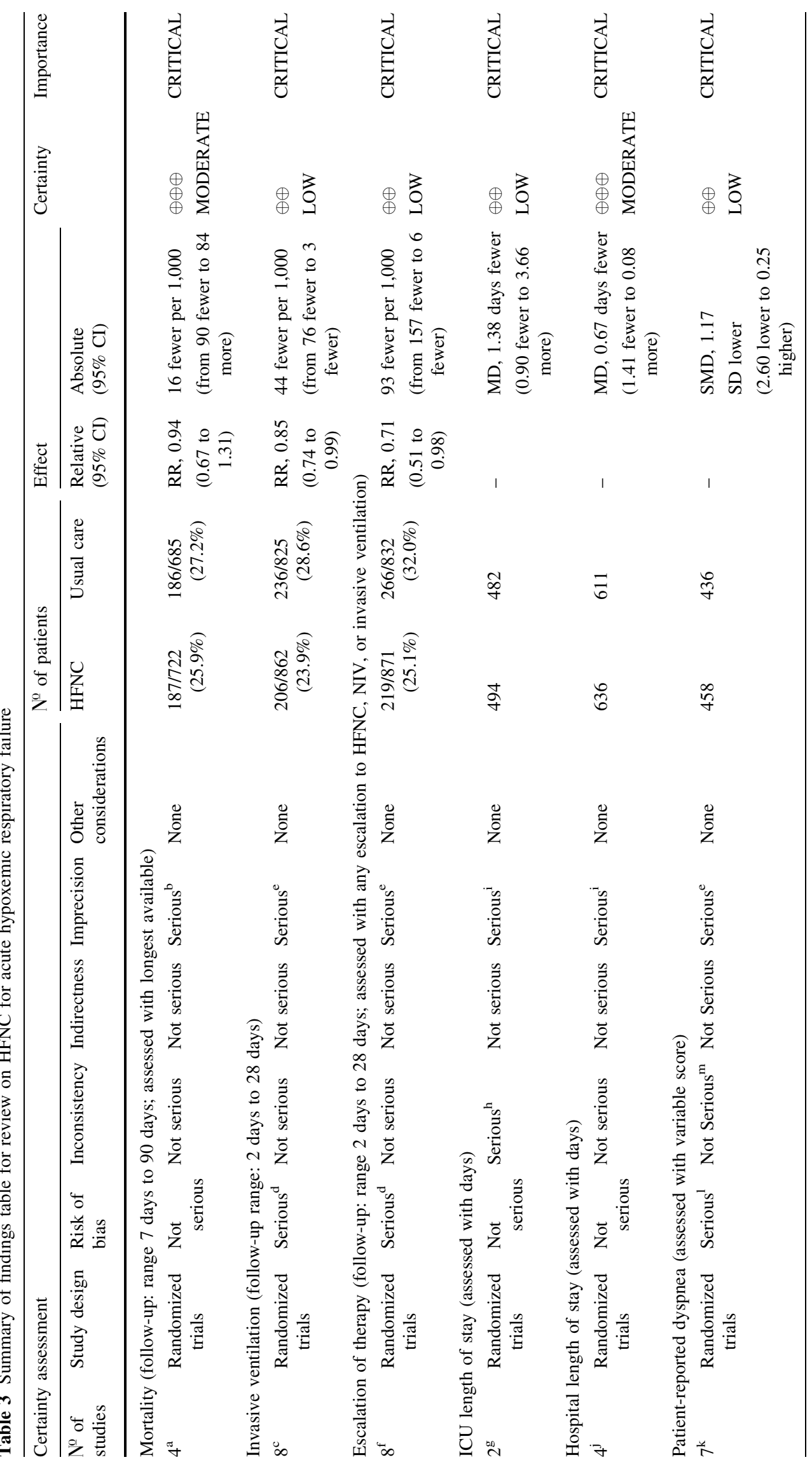




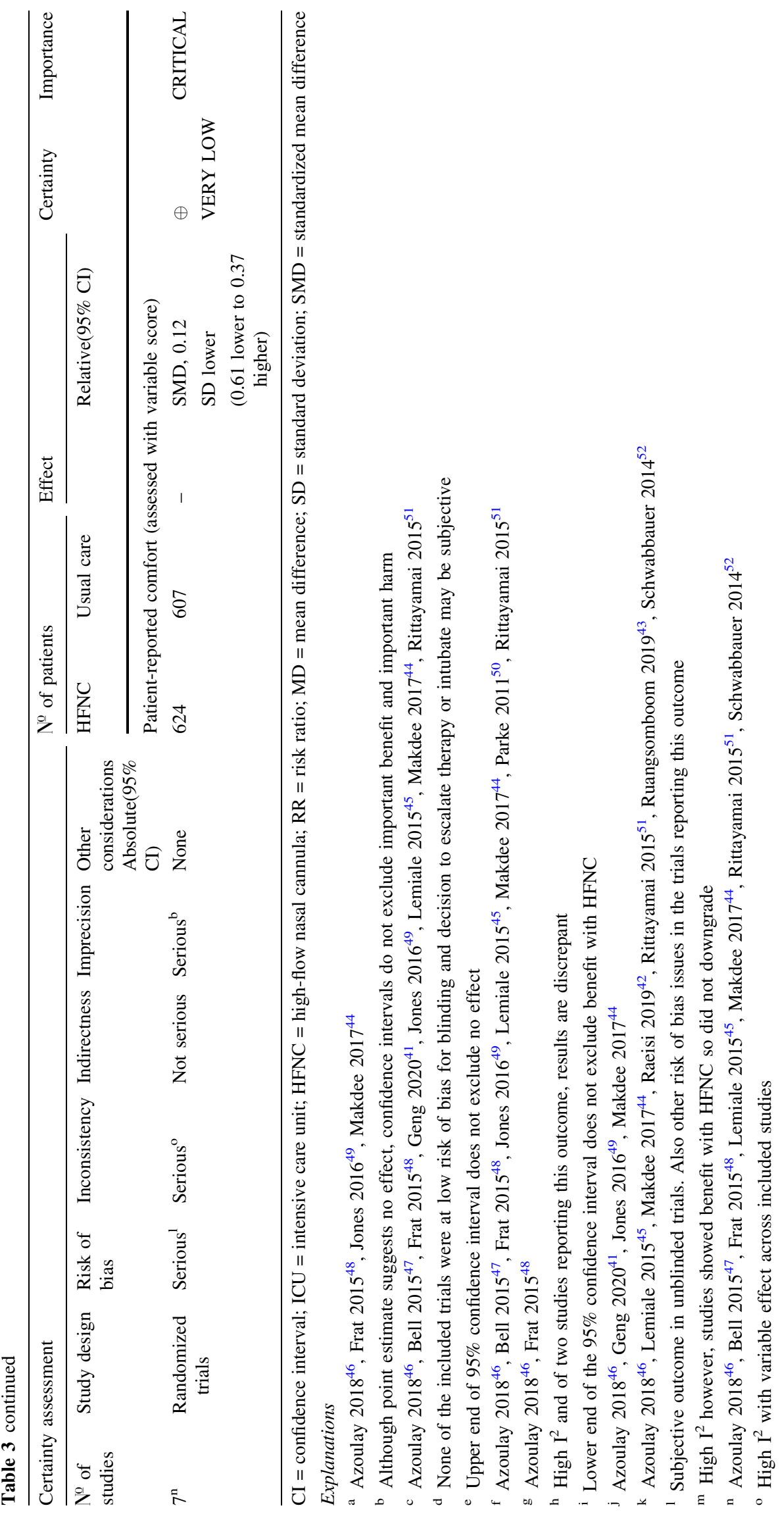


HFNC Standard O2 Risk Ratio

Study or Subgroup Events Total Events Total Weight IV, Random, 95\% CI 1.5.1 Low or Probably Low ROB

\begin{tabular}{lrrrrrr} 
Azoulay 201B & 150 & $3 B B$ & 170 & $3 B B$ & $36.0 \%$ & $0.8 B[0.75,1.04]$ \\
Frat 2015 & 45 & 106 & 51 & 94 & $30.4 \%$ & $0.7 B[0.59,1.04]$ \\
Makdee 2017 & 2 & 63 & 3 & 65 & $3.2 \%$ & $0.69[0.12,3.98]$ \\
Parke 2011 & 3 & 29 & 12 & 27 & $6.8 \%$ & $0.23[0.07,0.74]$ \\
Subtotal $(95 \% \mathrm{Cl})$ & \multicolumn{7}{c}{586} & & 574 & $76.4 \%$ & $0.78[0.59,1.03]$ \\
Total events & 200 & &
\end{tabular}

1.5.2 High or Probably High ROB

$\begin{array}{lrrrrrr}\text { Bell 2015 } & 2 & 4 B & 10 & 52 & 4.5 \% & 0.22[0.05,0.94] \\ \text { Jones 2016 } & 9 & 165 & 16 & 138 & 12.2 \% & 0.47[0.21,1.03] \\ \text { Lemlale 2015 } & 8 & 52 & 4 & 4 B & 6.9 \% & 1.85[0.59,5.74] \\ \text { Rittayamal 2015 } & 0 & 20 & 0 & 20 & & \text { Not estimable } \\ \text { Subtotal }(95 \% \mathrm{Cl}) & & 285 & & 258 & 23.6 \% & 0.60[0.20,1.81] \\ \text { Total events } & 19 & & 30 & & & \end{array}$

Heterogenelty: $\mathrm{Tau}^{2}=0.63 ; \mathrm{Ch}^{2}=5.99, \mathrm{df}=2(\mathrm{P}=0.05) ; \mathrm{P}^{2}=67 \mathrm{x}$

Test for overall effect: $Z=0.91(P=0.36)$
Risk Ratio

IV, Random, 95\% CI

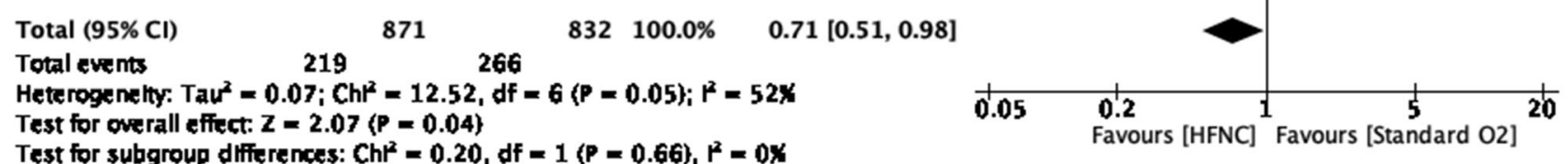

Fig. 3 Escalation of therapy forest plot for review on HFNC for acute hypoxemic respiratory failure. $\mathrm{CI}=$ confidence interval; $\mathrm{HFNC}=$ highflow nasal cannula; $\mathrm{RoB}=$ risk of bias

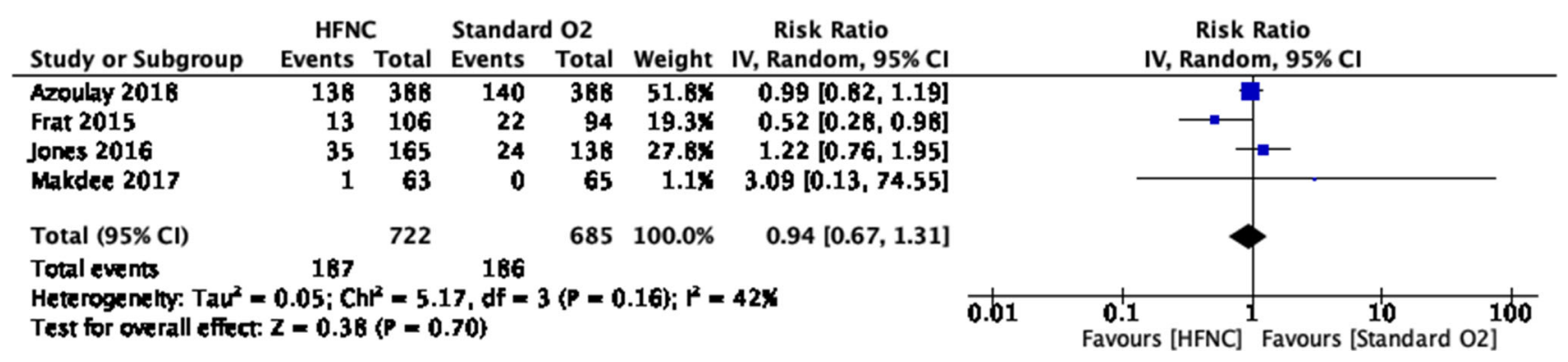

Fig. 4 Mortality forest plot for review on HFNC for acute hypoxemic respiratory failure. CI = confidence interval; HFNC = high-flow nasal cannula

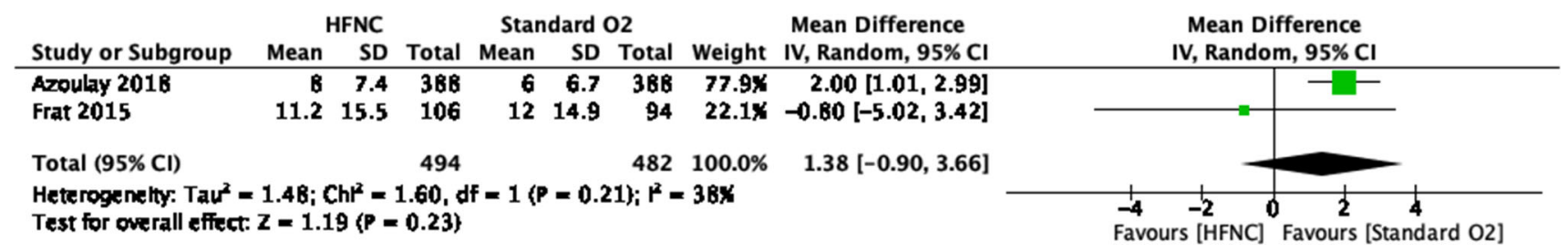

Fig. 5 Intensive care unit length of stay forest plot for review on HFNC for acute hypoxemic respiratory failure. $\mathrm{CI}=\mathrm{confidence}$ interval; HFNC $=$ high-flow nasal cannula

negative bacterial pneumonia. They evaluated the degree of environmental bacterial contamination with HFNC vs simple face mask oxygen. The study measured airborne and surface contaminants using an Andersen-type impactor air sampler and Petri dishes, respectively. No significant differences were found in gram-negative bacterial counts between HFNC and simple face mask oxygen in air samples, Petri dishes at $0.4 \mathrm{~m}$ (bedside rails) or $1.5 \mathrm{~m}$ (longest distance consistently achievable in the room) from the patient's nose, or with different air changes per hour $(P$ $=0.119$ to 0.500 across comparisons). ${ }^{56}$ 


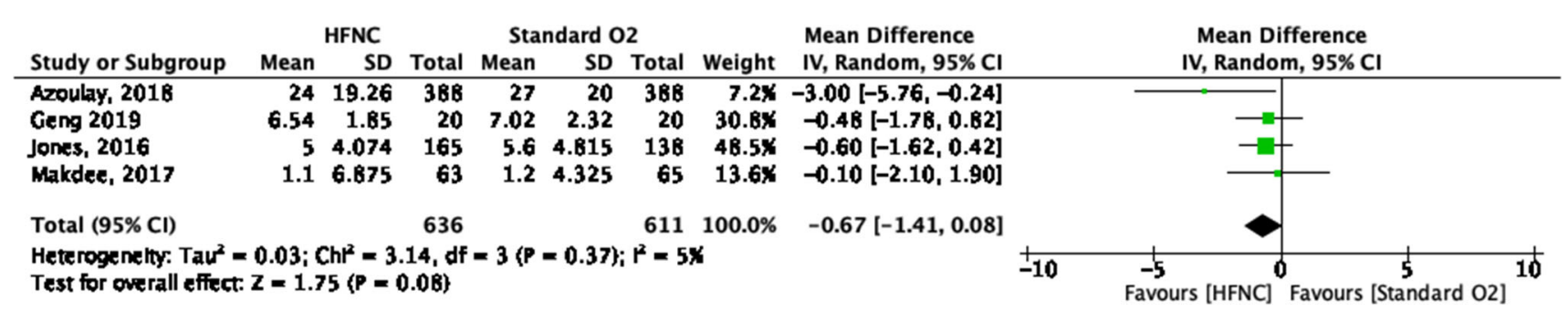

Fig. 6 Hospital length of stay forest plot for review on HFNC for acute hypoxemic respiratory failure. $\mathrm{CI}=$ confidence interval; $\mathrm{HFNC}=\mathrm{high}-$ flow nasal cannula

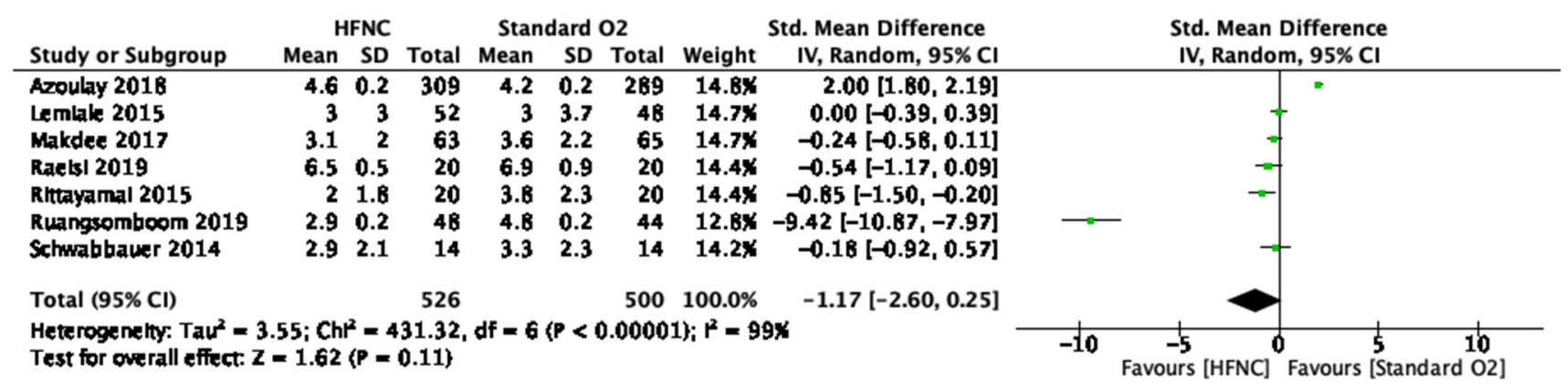

Fig. 7 Patient-reported dyspnea forest plot for review on HFNC for acute hypoxemic respiratory failure. $\mathrm{CI}=$ confidence interval; $\mathrm{HFNC}=$ highflow nasal cannula

\begin{tabular}{|c|c|c|c|c|c|c|c|c|}
\hline \multirow[b]{2}{*}{ Study or Subgroup } & \multicolumn{3}{|c|}{ HFNC } & \multicolumn{3}{|c|}{ Standard $\mathrm{O2}$} & \multicolumn{2}{|r|}{ Std. Mean Difference } \\
\hline & Mean & SD & Total & Mean & SD & Total & Weight & IV, Random, 95\% CI \\
\hline Azoulay 2018 & 3.7 & 0.2 & 321 & 3.6 & 0.2 & 314 & $16.0 \%$ & $0.50[0.34,0.66]$ \\
\hline Bell 2015 & 2 & 0.7 & 48 & 3 & 1.5 & 52 & $14.6 \%$ & $-0.84[-1.25,-0.43]$ \\
\hline Frat 2015 & 29 & 26 & 106 & 40 & 29 & 94 & $15.4 \%$ & $-0.40[-0.68,-0.12]$ \\
\hline Lembale 2015 & 3 & 3 & 52 & 3 & 3.7 & 48 & $14.7 x$ & $0.00[-0.39,0.39]$ \\
\hline Makdee 2017 & B.1 & 2 & 63 & 6.4 & 1.9 & 65 & $14.9 \%$ & $0.87[0.50,1.23]$ \\
\hline Rittayamal 2015 & 1.6 & 1.7 & 20 & 3.7 & 2.4 & 20 & $12.5 \%$ & $-0.99[-1.65,-0.33]$ \\
\hline Schwabbaucer 2014 & 2.7 & 1.8 & 14 & 3.1 & 2.8 & 14 & $11.8 \%$ & $-0.16[-0.91,0.58]$ \\
\hline Total $(95 \% \mathrm{Cl})$ & & & 624 & & & 607 & $100.0 \%$ & $-0.12[-0.61,0.3$ \\
\hline
\end{tabular}

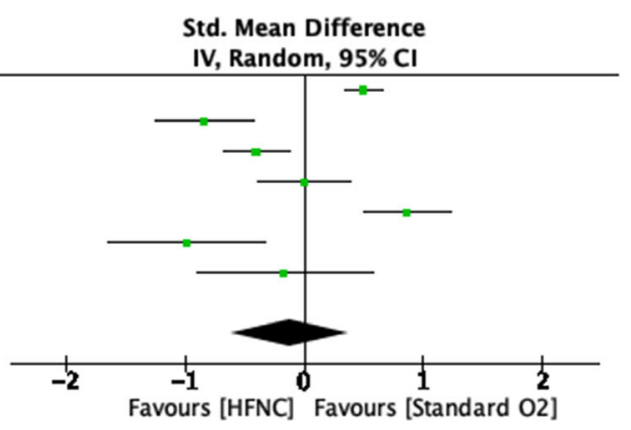

Fig. 8 Patient-reported comfort forest plot for review on HFNC for acute hypoxemic respiratory failure $\mathrm{CI}=$ confidence interval; $\mathrm{HFNC}=\mathrm{high}-$ flow nasal cannula

\section{Quality assessment}

There was concern for substantial RoB in design and conduct across all seven studies. Available evidence was significantly limited by small sample sizes with healthy volunteers or simulations, and in the absence of any studies directly including COVID-19 patients or evaluating aerosolization of similar microbes, by indirectness in applying findings to SARS-CoV-2 aerosolization and COVID-19 management. Based on GRADE guidance, there was very low certainty in estimates due to inconsistency in the magnitude and direction of the association between HFNC and aerosol and droplet dispersion across studies, as well as indirectness and imprecision.

\section{Discussion}

Our SRs - neither of which identified studies with direct evidence on COVID-19-provide limited but nevertheless the best current synthesis of the evidence on the benefits, harms, and risks of SARS-CoV-2 transmission through HFNC. Whereas HFNC applied in acute hypoxemic respiratory failure may substantially reduce the need for invasive ventilation and escalation of therapy to other NIV or intubation, we found no apparent differences in mortality, ICU/hospital LOS, patient-reported dyspnea and comfort, or differences in treatment-related complications. In the second systematic review on aerosol generation associated with HFNC, we found no studies directly related to COVID-19. Very low certainty 
Table 4 Complications from included studies for systematic review 1 on HFNC for acute hypoxemic respiratory failure

\begin{tabular}{|c|c|c|}
\hline & HFNC & Standard $\mathrm{O}_{2}$ \\
\hline Makdee, $2017^{44}$ & $n=63$ & $n=65$ \\
\hline Thoracic and cervical discomfort & 2 & 0 \\
\hline Feeling hot & 4 & 0 \\
\hline Jones, $2016^{49}$ & $n=165$ & $n=138$ \\
\hline Apnea & 0 & 1 \\
\hline Drop in GCS of 2 or more points & 1 & 6 \\
\hline Fall in GCS due to $\mathrm{CO}_{2}$ retention & 0 & 3 \\
\hline Raeisi, $2019^{42}$ & $n=20$ & $n=20$ \\
\hline Device-induced heat & 2 & 0 \\
\hline Nasal irritation & 2 & 0 \\
\hline Refractory asthma/hypoxia & 0 & 1 \\
\hline Rittayamai, $2015^{51}$ & $n=20$ & $n=20$ \\
\hline Unpleasant smell & 1 & 0 \\
\hline Temperature too warm & 1 & 0 \\
\hline Chest discomfort & 1 & 0 \\
\hline Ruangsomboon, $2019^{43}$ & $n=44$ & $n=44$ \\
\hline Discomfort & 5 & 0 \\
\hline Feeling hot & 2 & 0 \\
\hline Could not tolerate HFNC & 1 & 0 \\
\hline Frat, $2015^{48}$ & $n=106$ & $n=94$ \\
\hline Cardiac dysrhythmia & 11 & 16 \\
\hline Septic shock & 19 & 26 \\
\hline Cardio-respiratory arrest & 5 & 7 \\
\hline Nosocomial pneumonia & 4 & 8 \\
\hline Azoulay, $2018^{46}$ & $n=388$ & $n=388$ \\
\hline ICU-acquired infection & 39 & 41 \\
\hline
\end{tabular}

Makdee 2017 included aspiration and nasal ulceration but no events occurred in either group

Jones 2016 included pneumothorax, subcutaneous emphysema, and nasal pressure sore but no events occurred in either group

Bell 2015 reported that no adverse events occurred in either group

ICU = intensive care unit; GCS = Glasgow Coma Scale; HFNC = high-flow nasal cannula

experimental and observational data suggested mixed findings in terms of significant droplet dispersion and aerosol generation with HFNC.

Our findings bear direct relevance for all countries and healthcare systems and hospitals affected by the COVID19 pandemic, of which many are now forced to consider the use of HFNC in patients with acute respiratory failure due to COVID-19 in the face of limited access to invasive ventilation strategies.

The studies identified by our search do not provide data that can be extrapolated to the risk of airborne transmission of SARS-CoV-2. Among included studies, four examined dispersion of particles of droplet or larger size. ${ }^{54,55,57,59}$ Two studies were unable to show dispersion of live bacteria and yeast to a distance compatible with airborne dispersion ${ }^{55,56}$; however, this may reflect an inability of these organisms to survive the process of dehydration and rehydration, ${ }^{18}$ whereas SARS-CoV2 is known to survive aerosolization. ${ }^{60}$ One study identified a smaller region of high aerosol density around HFNC than nasal CPAP but did not quantify the total amount of aerosol generated by $\mathrm{HFNC}^{53}$; another showed comparable aerosol production levels with HFNC compared with COT strategies at distances close to the head, but the testing environment included multiple potential sources of aerosol generation, which may have obscured any increase due to HFNC. ${ }^{58}$

In terms of droplet dispersion, one study ${ }^{54}$ showed coughing while receiving HFNC may result in the dispersion of droplets further than 2 metres (i.e., beyond the distance typically considered the extent of droplet dispersion) ${ }^{61}$ suggesting that the area around a patient in which droplet precautions are applied may need to be 


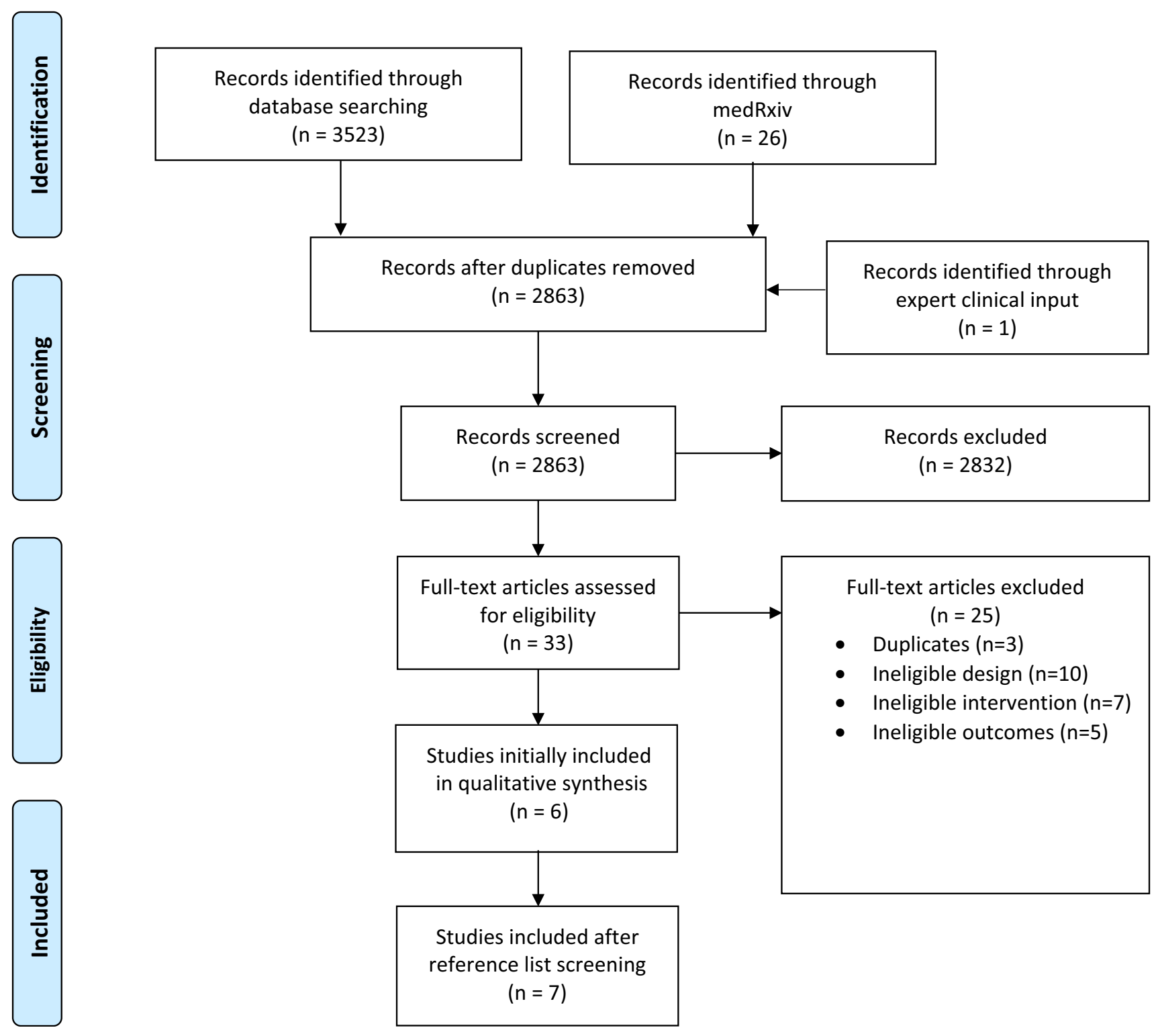

Fig. 9 PRISMA flow diagram for systematic review 2 on aerosol generation associated with HFNC. SR = systematic reviews; RCT = randomized-controlled trial

increased when HFNC is used. The applicability of findings among healthy adults during forceful exhalation to critically ill patients is uncertain.

The burden of COVID-related respiratory failure is straining ICU resources, ${ }^{62}$ and anecdotal evidence suggests mechanical ventilators may be insufficient for the patients that require them. In this context, a significant reduction in the need for invasive ventilation with HFNC may be of substantial benefit. Against this benefit, however, is the unknown risk of nosocomial transmission of SARS-CoV-2, and therefore any strong recommendation regarding the use of HFNC is clearly inappropriate. Instead, decisions should be context specific, taking into account the availability of invasive ventilation and the presence of other factors that decrease the risk of infection transmission. These include adequate room ventilation, limiting healthcare personnel exposure to the patient, viral load, and use of high-filtration fit-tested respirators (e.g., N95, FFP2) for healthcare workers. ${ }^{63}$ Use of a surgical face mask on patients receiving HFNC may also provide benefit. ${ }^{57}$ Ongoing field experiments and clinical studies during the current pandemic may provide additional information.

The risks and benefits of HFNC must also be balanced against the risks and benefits of alternatives, when 
Table 5 Characteristics of included studies for systematic review 2 on aerosol generation associated with HFNC

\begin{tabular}{|c|c|c|c|c|c|}
\hline Study & $n$ & Sample & Intervention/control & Outcome & Results \\
\hline $\begin{array}{l}\text { Roberts, } \\
2015^{59}\end{array}$ & $\mathrm{~N} / \mathrm{A}$ & Healthy adults & $\begin{array}{l}\mathrm{HFNC} \text { at } 30 \text { and } 60 \mathrm{~L} \cdot \mathrm{min}^{-1} \\
\text { compared with no HFNC at rest } \\
\text { and during violent exhalation }\end{array}$ & $\begin{array}{l}\text { Aerosol dispersion of particles } \\
25-250 \mu \mathrm{m} \text { in diameter }\end{array}$ & $\begin{array}{l}\text { HFNC did not increase aerosol } \\
\text { dispersion above risk of typical } \\
\text { breathing with violent } \\
\text { exhalation } \\
\text { With and without HFNC, aerosols } \\
25-250 \mu \mathrm{m} \text { travelled up to } 4.4 \\
\mathrm{~m} \text { and remained airborne for up } \\
\text { to } 43 \mathrm{sec}\end{array}$ \\
\hline $\begin{array}{l}\text { Hui, } \\
\qquad 2019^{53}\end{array}$ & $\mathrm{~N} / \mathrm{A}$ & $\begin{array}{l}\text { Patient } \\
\text { simulator }\end{array}$ & $\begin{array}{l}\mathrm{HFNC} \text { at } 10-60 \mathrm{~L} \cdot \mathrm{min}^{-1} \text { to } \mathrm{CPAP} \text { at } \\
5-20 \mathrm{~cm} \mathrm{H} \mathrm{H}_{2} \mathrm{O}\end{array}$ & $\begin{array}{l}\text { Regions of high exhaled aerosol } \\
\text { density following injection of } \\
\text { smoke into simulator bronchus }\end{array}$ & $\begin{array}{l}\text { Increased regions of high aerosol } \\
\text { density were noted with } \\
\text { increasing flow rates } \\
\text { (maximum dimension } 6.5 \pm 1.5 \\
\mathrm{~cm} \text { at } 10 \mathrm{~L} \cdot \mathrm{min}^{-1} \text { to } 17.2 \pm 3.3 \\
\mathrm{~cm} \text { at } 60 \mathrm{~L} \cdot \mathrm{min}^{-1} ; P<0.001 \text { ) } \\
\text { and increasing positive pressure } \\
\text { using CPAP. }\end{array}$ \\
\hline $\begin{array}{l}\text { Leung, } \\
2018^{56}\end{array}$ & 19 & $\begin{array}{l}\text { Critically ill } \\
\text { patients } \\
\text { with Gram- } \\
\text { negative } \\
\text { pneumonia }\end{array}$ & $\mathrm{HFNC}$ at $60 \mathrm{~L} \cdot \mathrm{min}^{-1}$ to $\mathrm{O}_{2}$ mask & $\begin{array}{l}\text { Cough-generated droplet } \\
\text { dispersion based on degree of } \\
\text { environmental bacterial } \\
\text { contamination }\end{array}$ & $\begin{array}{l}\text { No difference in GNB count } \\
\text { between HFNC and } \mathrm{O}_{2} \text { mask } \\
\text { for air samples, settle plates at } \\
0.4 \mathrm{~m} \text { or } 1.5 \mathrm{~m}(P=0.119- \\
0.500)\end{array}$ \\
\hline $\begin{array}{l}\text { Kotoda, } \\
2019^{55}\end{array}$ & $\mathrm{~N} / \mathrm{A}$ & $\begin{array}{l}\text { Mannequin } \\
\text { simulator }\end{array}$ & $\begin{array}{l}\text { HFNC at } 60 \mathrm{~L} \cdot \mathrm{min}^{-1} \text { compared with } \\
\text { HFNC at } 0 \mathrm{~L} \cdot \mathrm{min}^{-1}\end{array}$ & $\begin{array}{l}\text { Droplet dispersion determined by } \\
\text { measuring distance of water on } \\
\text { water-sensitive paper and } \\
\text { dispersion of live yeast }\end{array}$ & $\begin{array}{l}\text { Water and yeast colony formation } \\
\text { were detected on sheet placed } \\
\text { at } 30 \mathrm{~cm} \text { from mannequin's } \\
\text { face }(3.7 \pm 1.2 \text { spots and } 2.3 \pm \\
0.5 \text { yeast CFU) during use of } \\
\text { HFNC. }\end{array}$ \\
\hline $\begin{array}{l}\text { Loh, } \\
\qquad 2020^{54}\end{array}$ & 5 & Healthy adults & $\begin{array}{l}\text { HFNC at } 60 \mathrm{~L} \cdot \mathrm{min}^{-1} \text { compared with } \\
\text { no HFNC }\end{array}$ & $\begin{array}{l}\text { Cough-generated droplet } \\
\text { dispersion determined by } \\
\text { measuring distance of food } \\
\text { colouring droplet }\end{array}$ & $\begin{array}{l}\text { Similar droplet dispersion } \\
\text { distance }(2.91 \pm 1.09 \mathrm{~m}) \text { with } \\
\text { HFNC compared with no } \\
\text { HFNC }(2.48 \pm 1.03 \mathrm{~m}) . \\
\text { Highest cough-generated droplet } \\
\text { dispersion distances with } \\
\text { simulated coughs were } 450 \mathrm{~cm} \\
\text { and } 390 \mathrm{~cm} \text { with and without } \\
\text { HFNC, respectively. }\end{array}$ \\
\hline $\begin{array}{l}\text { Leonard, } \\
2020^{57}\end{array}$ & $\mathrm{~N} / \mathrm{A}$ & $\begin{array}{l}\text { In silico } \\
\text { simulator }\end{array}$ & $\begin{array}{l}\text { HFNC at } 40 \mathrm{~L} \cdot \min ^{-1} \text { compared with } \\
\text { nasal prongs at } 6 \mathrm{~L} \cdot \mathrm{min}^{-1} \text { and } \\
\text { spontaneous breathing (all with } \\
\text { face mask) }\end{array}$ & $\begin{array}{l}\text { Intentional mask leak, droplet } \\
\text { capture by face mask, droplet } \\
\text { dispersion from point of origin. }\end{array}$ & $\begin{array}{l}\text { Greater leak }(16.5 \%) \text { with HFNC } \\
\text { compared with nasal prongs } \\
(12.6 \%) \text { and spontaneous } \\
\text { breathing }(11.6 \%) \text {. } \\
\text { Droplets captured by face mask } \\
\text { were variable with HFNC } \\
(85.9 \%) \text {, nasal prongs }(75.9 \%) \\
\text { and spontaneous breathing } \\
(89.9 \%) \text {. } \\
\text { Variable proportions of escaped } \\
\text { particles travelled greater than } \\
1 \text { metre from point of origin } \\
\text { with HFNC (15.9\%) compared } \\
\text { with nasal prongs }(6.9 \%) \text { and } \\
\text { spontaneous breathing }(31 \%) .\end{array}$ \\
\hline
\end{tabular}


Table 5 continued

\begin{tabular}{|c|c|c|c|c|c|}
\hline Study & $n$ & Sample & Intervention/control & Outcome & Results \\
\hline $\begin{array}{c}\text { Iwashyna, } \\
2020^{58}\end{array}$ & 4 & Healthy adults & $\begin{array}{l}\mathrm{HFNC} \text { at } 30 \mathrm{~L} \cdot \mathrm{min}^{-1} \text { and } 60 \mathrm{~L} \cdot \mathrm{min}^{-1} \\
\text { compared with nasal cannula } 6 \\
\mathrm{~L} \cdot \mathrm{min}^{-1} \text { and non-rebreather mask } \\
\text { (non-humidified) at } 15 \mathrm{~L} \cdot \mathrm{min}^{-1} \text {. }\end{array}$ & $\begin{array}{l}\text { Aerosol levels of particles } 10-500 \\
\text { nm in size with spontaneous } \\
\text { breathing and intentional } \\
\text { coughing, measured at bed rail } \\
\text { beside patient's head and } 10 \mathrm{~cm} \\
\text { from patient's mouth }\end{array}$ & $\begin{array}{l}\text { Similar aerosol levels with HFNC } \\
\text { at } 30 \mathrm{~L} \cdot \mathrm{min}^{-1} \text { and } 60 \mathrm{~L} \cdot \mathrm{min}^{-1} \text {, } \\
\text { nasal prongs at } 6 \mathrm{~L} \cdot \mathrm{min}^{-1}, 15 \\
\mathrm{~L} \cdot \mathrm{min}^{-1} \text { non-rebreather mask } \\
\text { and spontaneous breathing at } \\
\text { room air. } \\
\text { Similar particle number } \\
\text { concentration (across all } \\
\text { particle sizes) with HFNC } \\
\text { compared with other } \\
\text { interventions. }\end{array}$ \\
\hline
\end{tabular}

$\mathrm{CFU}=$ colony forming units; $\mathrm{CPAPs}=$ continuous positive airway pressure, $\mathrm{GNB}=$ gram-negative bacteria; $\mathrm{HFNC}=$ high-flow nasal cannula

available. A recent guideline made no recommendation regarding use of NIV for de novo hypoxemic respiratory failure or pandemic viral illness. ${ }^{64}$ Both NIV and invasive ventilation were associated with nosocomial transmission of SARS, ${ }^{65,66}$ although some simulation data suggest that NIV is not an aerosol-generating procedure. ${ }^{67}$ Therefore, optimal management may differ across settings, depending on the availability of ventilators and other NIV modalities.

The strengths of the first of our two SRs reported herein include a comprehensive literature search with the inclusion of the most recent trial evidence. We systematically and transparently assessed the certainty and relevance of the identified evidence through the use of GRADE. Inherent limitations in the available evidence include lack of sufficient data to explore certain subgroup effects, imprecision, and high RoB due to lack of blinding. No eligible RCTs included COVID-19 patients; however, we did not rate down for indirectness, given the likelihood that similar principles of management are applicable to COVID-19 patients with acute hypoxemic respiratory failure. Despite clinical heterogeneity in study populations and definitions of hypoxemia, most outcomes did not show statistical heterogeneity (i.e., consistency). One trial ${ }^{46}$ contributed approximately one-third of the data for most major outcomes and may affect generalizability of the findings. Finally, because of reporting variability, treatment-related complications could not be pooled for quantitative analyses.

Strengths of the second systematic review include a comprehensive literature search incorporating English and
Chinese studies and pre-prints, and inclusion of clinical expert input regarding aerosol generation and HFNC. Limitations include substantial RoB issues, indirectness in applying findings to SARS-CoV-2 aerosolization and COVID-19 management, imprecision with limited studies involving small samples of healthy individuals or simulations, and inconsistent experimental conditions and effects observed across studies.

\section{Conclusions}

We found that HFNC applied to patients with respiratory failure may substantially reduce the need for invasive ventilation and escalation of therapy to NIV or intubation (low certainty), with no apparent effect on mortality or patient-reported symptoms. Complications of therapy were comparable to COT modalities. Very low certainty evidence showed uncertain findings with regards to droplet dispersion and aerosol generation with HFNC. No direct evidence applicable to COVID-19 was available for either efficacy or infection-related risks.

Taken together, the benefits of HFNC in the face of the COVID-19 pandemic must be carefully balanced against the unknown risk of airborne transmission of infection to healthcare workers and other patients. As a result, and until further data specific to COVID are available, guidance and subsequent care decisions will need to be based on the specific context, including considerations around availability of personal protective equipment, a safe 
environment for HFNC delivery, ventilator resources, and individual patient values and preferences. Studies of COVID-19 with application of HFNC to appropriate patients are required to adequately assess this risk of infection transmission using viral samplers, reverse transcriptase polymerase chain reaction testing, and viral cultures.

Author contributions Per O. Vandvik conceived the study. Arnav Agarwal and Per O. Vandvik organized the study teams and process. Per O. Vandvik and Rachel Couban designed the search strategy. John Basmaji, Fiona Muttalib, David Granton, Dipayan Chaudhuri, Devin Chetan, Malini Hu, Shannon M. Fernando, Kimia Honarmand, Layla Bakaa, and Sonia Brar screened studies for eligibility, and assessed study RoB and certainty of the body of evidence. Arnav Agarwal addressed discrepancies in screening, data extraction, RoB, and GRADE assessments. Quazi Ibrahim and Arnav Agarwal conducted the data analysis. Arnav Agarwal, Bram Rochwerg, Neill K. Adhikari, Fiona Muttalib, Srinivas Murthy, David S.C. Hui, Charles Gomersall, Samira Mubareka, Janet V. Diaz, Karen E. A. Burns, Gordon H. Guyatt, and Per O. Vandvik were involved in interpretation of the data. Arnav Agarwal wrote the first draft of the manuscript and conducted data analysis. Arnav Agarwal, Bram Rochwerg, Neill K. Adhikari, Fiona Muttalib, Srinivas Murthy, David S.C. Hui, Charles Gomersall, Samira Mubareka, Janet V. Diaz, Karen E. A. Burns, Gordon H. Guyatt, and Per O. Vandvik critically revised the manuscript. Arnav Agarwal and Per O. Vandvik are the guarantors. All co-authors were involved in final editing of the manuscript. The corresponding author attests that all listed authors meet authorship criteria and that no others meeting the criteria have been omitted.

Acknowledgements We would like to thank Yaolong Chen, Xuan Yu, Nan Yang, and Xufei Luo for their assistance with systematic searching and screening of evidence from the China National Knowledge Infrastructure database for additional literature related to our systematic review focused on risk of aerosol generation with HFNC.
Patient and public involvement No patients were involved in this study, given the severe time constraints of seven days to completion for both WHO-commissioned rapid reviews.

Disclosures All authors provided disclosures of interest to the WHO in advance of completing the systematic reviews, of which none were considered to have relevant financial conflicts of interest.

Funding statement These rapid reviews were commissioned and paid for by the World Health Organization, and coordinated through the MAGIC Evidence Ecosystem Foundation (www.magicproject. org). The authors alone are responsible for the reviews expressed in this article, and they do not necessarily represent the decisions, policy or views of the World Health Organization. One co-author (Janet V. Diaz) is employed by the WHO and had no role in funding decisions for either rapid review.

Transparency The manuscript's guarantors (Per O. Vandvik and Arnav Agarwal) affirm that the manuscript is an honest, accurate, and transparent account of the recommendation being reported; that no important aspects of the recommendation have been omitted; and that any discrepancies from the recommendation as planned (and, if relevant, registered) have been explained.

Editorial responsibility This submission was handled by Dr. Hilary P. Grocott, Editor-in-Chief, Canadian Journal of Anesthesia.

Data sharing statement No additional data available.

\section{Appendix}

Appendix 1: Search strategy for review on HFNC for acute hypoxemic respiratory failure 


\section{MEDLINE}

Database: Ovid MEDLINE Epub Ahead of Print, In-Process \& Other Non-Indexed Citations, Ovid MEDLINE(R) Daily and Ovid MEDLINE(R) 1946 to Present

Search Strategy:

1 high flow nasal cannula.mp. (852)

2 high flow nasal therapy.mp. (23)

3 high flow nasal oxygen.mp. (150)

4 high flow oxygen therapy.mp. (170)

5 high flow therapy.mp. (84)

6 optiflow.mp. (51)

7 nasal highflow.mp. (7)

8 HFNC.mp. (437)

9 (((high adj2 flow) or highflow) adj4 oxygen*).mp. [mp=title, abstract, original title, name of substance word, subject heading word, floating sub-heading word, keyword heading word, organism supplementary concept word, protocol supplementary concept word, rare disease supplementary concept word, unique identifier, synonyms] (998)

10 ((nose or nasal or nostril*) adj4 (catheter or cannula)).mp. [mp=title, abstract, original title, name of substance word, subject heading word, floating sub-heading word, keyword heading word, organism supplementary concept word, protocol supplementary concept word, rare disease supplementary concept word, unique identifier, synonyms] (1890)

11 ((nose or nasal or nostril*) adj4 oxygen*).mp. [mp=title, abstract, original title, name of substance word, subject heading word, floating sub-heading word, keyword heading word, organism supplementary concept word, protocol supplementary concept word, rare disease supplementary concept word, unique identifier, synonyms] (1426)

1210 or $11(2644)$ 
13 ((high adj2 flow) or highflow or high or flow).mp. [mp=title, abstract, original title, name of substance word, subject heading word, floating sub-heading word, keyword heading word, organism supplementary concept word, protocol supplementary concept word, rare disease supplementary concept word, unique identifier, synonyms] (4606035)

$14 \quad 12$ and $13(1584)$

151 or 2 or 3 or 4 or 5 or 6 or 7 or 8 or 9 or $14(2136)$

16 Humans/ or human*.mp. (18999870)

17 Adult/ or adult.mp. (5535642)

18 mature.mp. (178988)

19 grown.mp. (155254)

20 or/16-19 (19499661)

$21 \quad 15$ and 20 (1571)

22 limit 21 to ed=20181001-20200326 (342)

Database: Embase <1974 to 2020 March 25>

Search Strategy:

1 high flow nasal cannula.mp. (1737)

2 high flow nasal therapy.mp. (36)

3 high flow nasal oxygen.mp. (294)

4 high flow oxygen therapy.mp. (331)

5 high flow therapy.mp. (192)

6 optiflow.mp. (302)

7 nasal highflow.mp. (16)

8 HFNC.mp. (971) 
9 (((high adj2 flow) or highflow) adj4 oxygen*).mp. [mp=title, abstract, heading word, drug trade name, original title, device manufacturer, drug manufacturer, device trade name, keyword, floating subheading word, candidate term word] (1991)

10 ((nose or nasal or nostril*) adj4 (catheter or cannula)).mp. [mp=title, abstract, heading word, drug trade name, original title, device manufacturer, drug manufacturer, device trade name, keyword, floating subheading word, candidate term word] (5310)

11 ((nose or nasal or nostril*) adj4 oxygen*).mp. [mp=title, abstract, heading word, drug trade name, original title, device manufacturer, drug manufacturer, device trade name, keyword, floating subheading word, candidate term word] (3087)

1210 or $11(6495)$

13 ((high adj2 flow) or highflow or high or flow).mp. [mp=title, abstract, heading word, drug trade name, original title, device manufacturer, drug manufacturer, device trade name, keyword, floating subheading word, candidate term word] (6262679)

$14 \quad 12$ and $13(3847)$

151 or 2 or 3 or 4 or 5 or 6 or 7 or 8 or 9 or $14(4987)$

16 Humans/ or human*.mp. (21585182)

17 Adult/ or adult.mp. (7458693)

18 mature.mp. (212893)

19 grown.mp. (161351)

20 or/16-19 (22229685)

$21 \quad 15$ and 20 (4613)

22 limit 21 to em=201836-202052 (1451)

Web of Science

\#21

296

Indexes=SCI-EXPANDED, SSCI, A\&HCI, CPCI-S, CPCI-SSH, BKCI-S, BKCISSH, ESCI, CCR-EXPANDED, IC Timespan $=2018-2020$

Edit

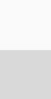


Indexes $=S C I-E X P A N D E D$, SSCI, A\&HCI, CPCI-S, CPCI-SSH, BKCI-S, BKCI-

SSH, ESCI, CCR-EXPANDED, IC Timespan=All years

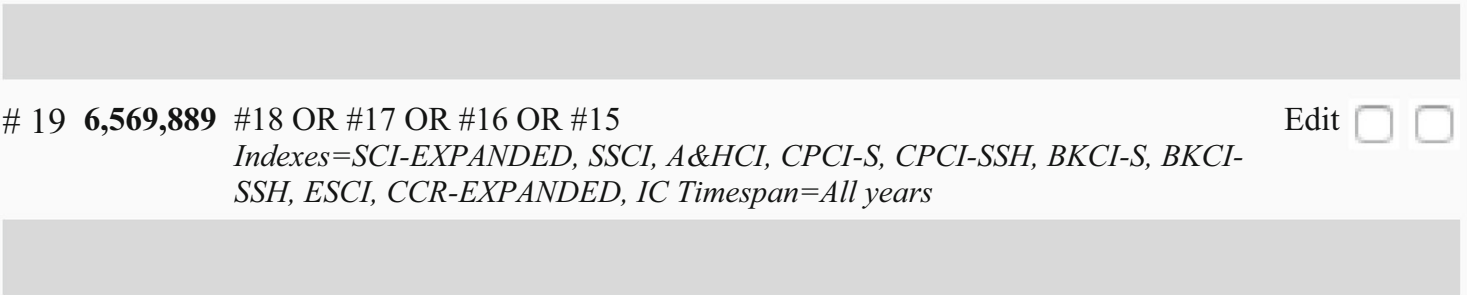

\# 18 1,277,040 TS=grown

Edit

Indexes $=S C I-E X P A N D E D$, SSCI, A\&HCI, CPCI-S, CPCI-SSH, BKCI-S, BKCI-

SSH, ESCI, CCR-EXPANDED, IC Timespan =All years

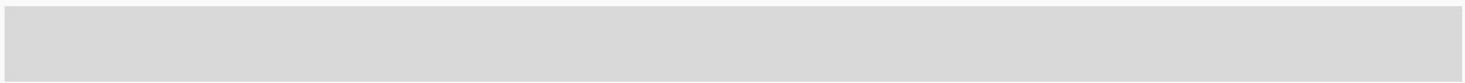

\# 17 260,081 TS=mature

Edit

Indexes $=S C I-E X P A N D E D, S S C I, A \& H C I, C P C I-S, C P C I-S S H, B K C I-S, B K C I-$

SSH, ESCI, CCR-EXPANDED, IC Timespan=All years

\# $16 \mathbf{1 , 4 9 1 , 6 9 1 ~} \begin{aligned} & \text { TS=adult } \\ & \text { Indexes=SCI-EXPANDED, SSCI, A\&HCI, CPCI-S, CPCI-SSH, BKCI-S, BKCI- } \\ & \text { SSH, ESCI, CCR-EXPANDED, IC Timespan=All years }\end{aligned}$

\# 15 3,928,250 TS=human*

Indexes $=S C I-E X P A N D E D$, SSCI, A\&HCI, CPCI-S, CPCI-SSH, BKCI-S, BKCI-

Edit SSH, ESCI, CCR-EXPANDED, IC Timespan=All years

\# $14 \quad \mathbf{5 , 9 6 9}$ \#13 OR \#10 OR \#9 OR \#8 OR \#7 OR \#6 OR \#5 OR \#4 OR \#3 OR \#2 OR \#1 Edit Indexes $=S C I-E X P A N D E D$, SSCI, A\&HCI, CPCI-S, CPCI-SSH, BKCI-S, BKCI-

SSH, ESCI, CCR-EXPANDED, IC Timespan=All years

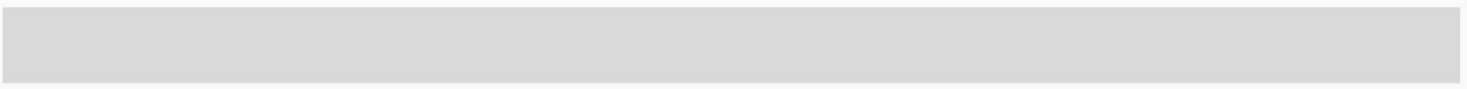

\# $13 \quad \mathbf{2 , 2 2 5} \quad \# 12$ AND \#11

Edit

Indexes $=S C I-E X P A N D E D$, SSCI, A\&HCI, CPCI-S, CPCI-SSH, BKCI-S, BKCI-

SSH, ESCI, CCR-EXPANDED, IC Timespan=All years

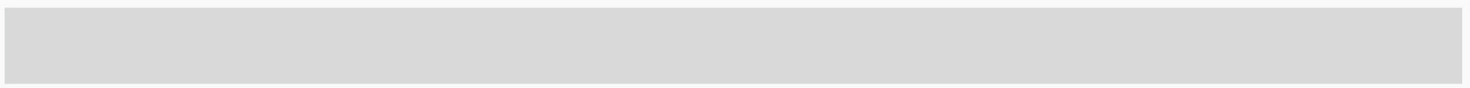

\# 12 12,909,976 TS=((high near/2 flow) or highflow or high or flow $)$

Indexes $=S C I-E X P A N D E D, S S C I, A \& H C I, C P C I-S, C P C I-S S H, B K C I-S, B K C I-$

SSH, ESCI, CCR-EXPANDED, IC Timespan=All years

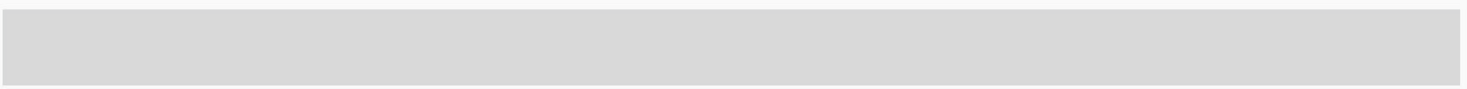

\section{\# $11 \quad \mathbf{3 , 1 8 2} \quad$ \#10 OR \#9}

Edit

Indexes $=S C I-E X P A N D E D, S S C I, A \& H C I, C P C I-S, C P C I-S S H, B K C I-S, B K C I-$

SSH, ESCI, CCR-EXPANDED, IC Timespan=All years 


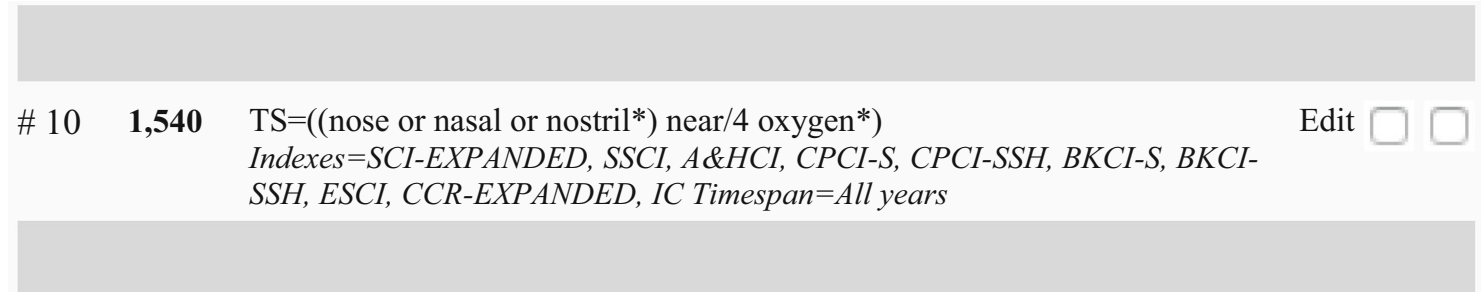

\# $9 \mathbf{2 , 4 5 2} \mathrm{TS}=(($ nose or nasal or nostril*) near/4 (catheter or cannula)).

Edit

Indexes $=S C I-E X P A N D E D$, SSCI, A\&HCI, CPCI-S, CPCI-SSH, BKCI-S, BKCI-

SSH, ESCI, CCR-EXPANDED, IC Timespan=All years

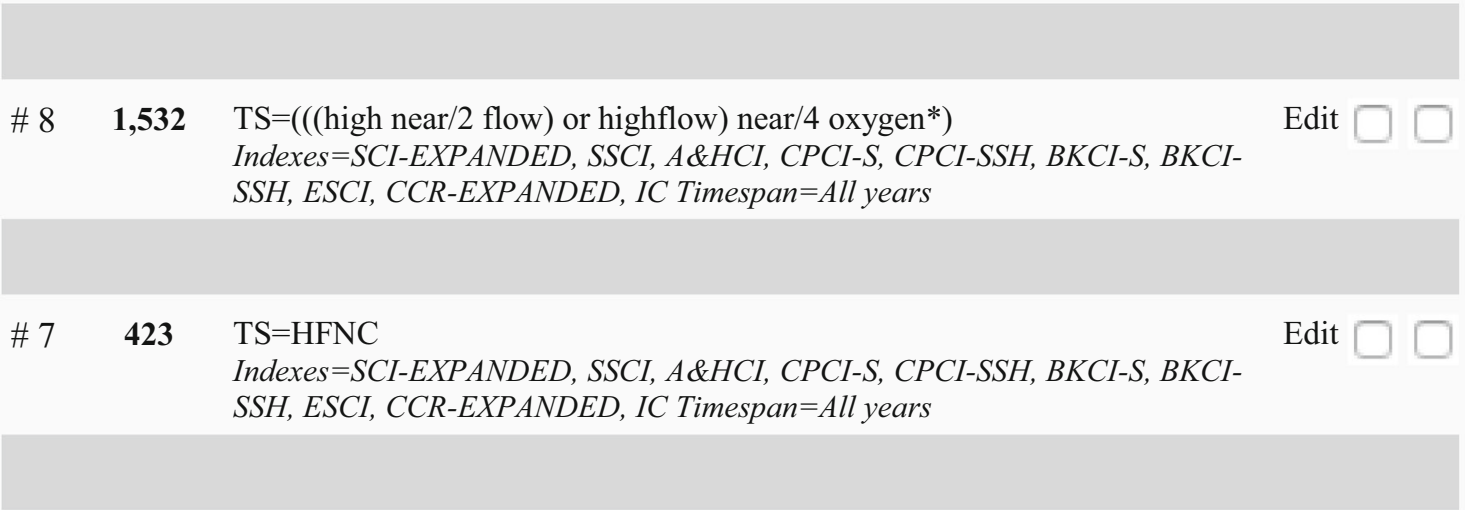

\# 616 TS=nasal highflow

Edit

Indexes $=S C I-E X P A N D E D$, SSCI, A\&HCI, CPCI-S, CPCI-SSH, BKCI-S, BKCI-

SSH, ESCI, CCR-EXPANDED, IC Timespan=All years

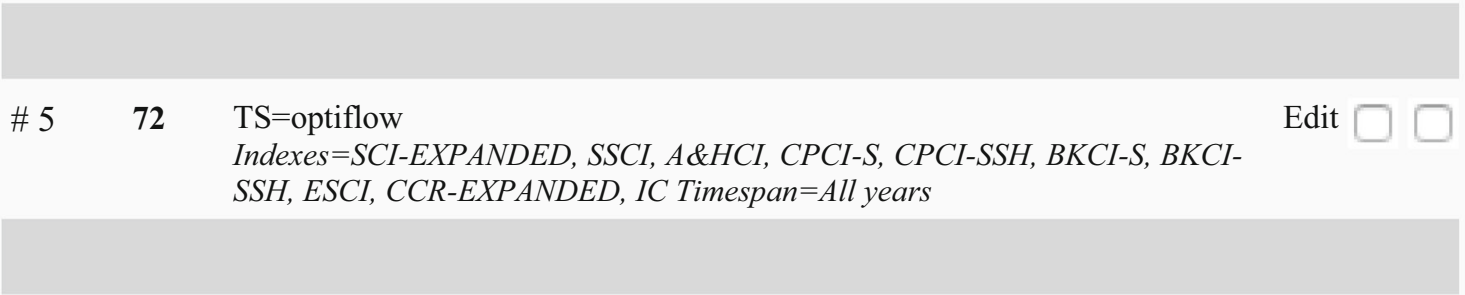

\# $4 \quad \mathbf{2 , 6 3 2}$ TS=high flow oxygen therapy

Edit

Indexes $=S C I-E X P A N D E D$, SSCI, A\&HCI, CPCI-S, CPCI-SSH, BKCI-S, BKCI-

SSH, ESCI, CCR-EXPANDED, IC Timespan=All years

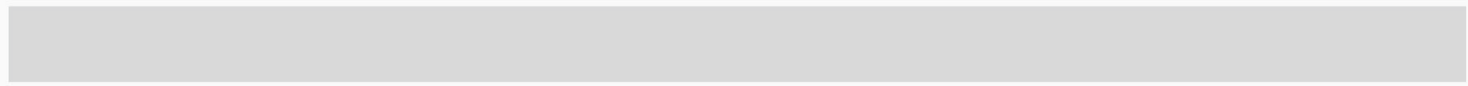

\# 3 1,268 TS=high flow nasal oxygen

Edit

Indexes $=S C I-E X P A N D E D$, SSCI, A\&HCI, CPCI-S, CPCI-SSH, BKCI-S, BKCI-

SSH, ESCI, CCR-EXPANDED, IC Timespan =All years

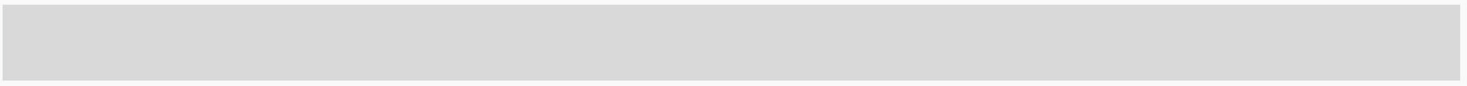

\# 2 1,211 TS=high flow nasal therapy

Edit

Indexes $=S C I-E X P A N D E D, S S C I, A \& H C I, C P C I-S, C P C I-S S H, B K C I-S, B K C I-$

SSH, ESCI, CCR-EXPANDED, IC Timespan=All years

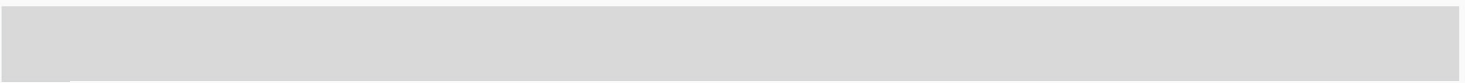

\# $1 \quad \mathbf{1 , 4 6 2}$ TS=high flow nasal cannula

Edit

Indexes $=S C I-E X P A N D E D$, SSCI, A\&HCI, CPCI-S, CPCI-SSH, BKCI-S, BKCI-

SSH, ESCI, CCR-EXPANDED, IC Timespan=All years 
Appendix 2: Search strategy for review on aerosol generation associated with HFNC.

\section{MEDLINE}

Database: Ovid MEDLINE Epub Ahead of Print, In-Process \& Other Non-Indexed Citations, Ovid MEDLINE(R) Daily and Ovid MEDLINE(R) 1946 to Present

Search Strategy:

$1 \exp$ Coronavirus/ (11467)

$2 \exp$ Coronavirus Infections/ (9776)

3 (coronavir* or coronovir* or SARS or MERS or MERS-COV or SARS-COV or SARS-COV2 or COV or NCOV or $2019 \mathrm{nCOV}$ or 2019-nCOV or COVID-19).mp. [mp=title, abstract, original title, name of substance word, subject heading word, floating sub-heading word, keyword heading word, organism supplementary concept word, protocol supplementary concept word, rare disease supplementary concept word, unique identifier, synonyms] (24352)

4 or/1-3 (26699)

5 Cannula/ (632)

6 Oxygen Inhalation Therapy/ (14148)

7 HFNC.mp. (438)

8 optiflow.mp. (51)

9 (((high adj2 flow) or highflow) adj4 oxygen*).mp. [mp=title, abstract, original title, name of substance word, subject heading word, floating sub-heading word, keyword heading word, organism supplementary concept word, protocol supplementary concept word, rare disease supplementary concept word, unique identifier, synonyms] (1000)

10 ((nose or nasal or nostril*) adj4 (catheter or cannula)).mp. [mp=title, abstract, original title, name of substance word, subject heading word, floating sub-heading word, keyword heading word, organism supplementary concept word, protocol supplementary concept word, rare disease supplementary concept word, unique identifier, synonyms] (1895)

11 ((nose or nasal or nostril*) adj4 oxygen*).mp. [mp=title, abstract, original title, name of substance word, subject heading word, floating sub-heading word, keyword heading word, organism supplementary concept word, protocol supplementary concept word, rare disease supplementary concept word, unique identifier, synonyms] (1427) 
12 or/5-11 (16515)

134 and $12(41)$

14 (infect* or pathogen* or contamina* or bacteria* or microbia* or virus or viral or virulent or dispers* or droplet* or partic* or aerosol* or environment* or transmiss* or transmit or safety* or commun* or contagi*).mp. [mp=title, abstract, original title, name of substance word, subject heading word, floating sub-heading word, keyword heading word, organism supplementary concept word, protocol supplementary concept word, rare disease supplementary concept word, unique identifier, synonyms] (8649840)

15 exp Disease Transmission, Infectious/ (67129)

1614 or $15(8656328)$

$17 \quad 12$ and $16(3564)$

18 limit 17 to $\mathrm{yr}=$ "2007 -Current" (1799)

1913 or $18(1823)$

20 or/7-11 (3144)

2116 and $20(867)$

22 limit 21 to $y r=" 2007$-Current" (677)

2313 or $22(706)$

\section{EMBASE}

Database: Embase $<1996$ to 2020 March 24>

Search Strategy:

1 exp coronavirinae/ (10512)

$2 \exp$ Coronavirus infection/ (11152)

3 (coronavir* or coronovir* or SARS or MERS or MERS-COV or SARS-COV or SARS-COV2 or COV or NCOV or 2019 nCOV or 2019-nCOV or COVID-19).mp. [mp=title, abstract, heading 
word, drug trade name, original title, device manufacturer, drug manufacturer, device trade name, keyword, floating subheading word, candidate term word] (25178)

4 or/1-3 (29171)

5 exp nasal cannula/ (4058)

6 *oxygen therapy/ (4420)

7 HFNC.mp. (968)

8 optiflow.mp. (302)

9 (((high adj2 flow) or highflow) adj4 oxygen*).mp. [mp=title, abstract, heading word, drug trade name, original title, device manufacturer, drug manufacturer, device trade name, keyword, floating subheading word, candidate term word] (1924)

10 ((nose or nasal or nostril*) adj4 (catheter or cannula)).mp. [mp=title, abstract, heading word, drug trade name, original title, device manufacturer, drug manufacturer, device trade name, keyword, floating subheading word, candidate term word] (5045)

11 ((nose or nasal or nostril*) adj4 oxygen*).mp. [mp=title, abstract, heading word, drug trade name, original title, device manufacturer, drug manufacturer, device trade name, keyword, floating subheading word, candidate term word] (2808)

12 or/5-11 (10728)

134 and $12(30)$

14 (infect* or pathogen* or contamina* or bacteria* or microbia* or virus or viral or virulent or dispers* or droplet* or partic* or aerosol* or environment* or transmiss* or transmit or safety* or commun* or contagi*).mp. (8963763)

15 exp disease transmission/ (201378)

1614 or $15(8969037)$

17 or/7-11 (7007)

$18 \quad 16$ and $17(2733)$

19 limit 18 to $\mathrm{yr}=" 2007$-Current" (2589)

2013 or $19(2598)$ 


\section{References}

1. Zhu $N$, Zhang $D$, Wang $W$, et al. A novel coronavirus from patients with pneumonia in China, 2019. N Engl J Med 2020; 382: 727-33.

2. World Health Organization. Rolling updates on coronavirus disease (COVID-19). Available from URL: https://www.who.int/ emergencies/diseases/novel-coronavirus-2019/events-as-theyhappen (accessed May 2020).

3. John Hopkins University of Medicine Coronavirus Resource Centre. COVID-19 dashboard by the Center for Systems Science and Engineering (CSSE) at John Hopkins University (JHU). Available from URL: https://coronavirus.jhu.edu/map.html (accessed May 2020).

4. Wu Z, McGoogan JM. Characteristics of and important lessons from the coronavirus disease 2019 (COVID-19) outbreak in China: summary of a report of 72,314 cases from the Chinese Center for Disease Control and Prevention. JAMA 2020; DOI: https://doi.org/10.1001/jama.2020.2648.

5. Epidemiology Working Group for NCIP Epidemic Response, Chinese Center for Disease Control and Prevention. The epidemiological characteristics of an outbreak of. novel coronavirus diseases (COVID-19) in China (Chinese). Zhonghua Liu Xing Bing Xue Za Zhi. 2019; 2020(41): 145-51.

6. Antonelli $M$, Conti $G$, Rocco $M$, et al. A comparison of noninvasive positive-pressure ventilation and conventional mechanical ventilation in patients with acute respiratory failure. N Engl J Med 1998; 339: 429-35.

7. Carrillo A, Gonzalez-Diaz G, Ferrer M, et al. Non-invasive ventilation in community-acquired pneumonia and severe acute respiratory failure. Intensive Care Med 2012; 38: 458-66.

8. Delclaux C, L'Her E, Alberti C, et al. Treatment of acute hypoxemic nonhypercapnic respiratory insufficiency with continuous positive airway pressure delivered by a face mask: a randomized controlled trial. JAMA 2000; 284: 2352-60.

9. Hilbert $G$, Gruson D, Vargas $F$, et al. Noninvasive continuous positive airway pressure in neutropenic patients with acute respiratory failure requiring intensive care unit admission. Crit Care Med 2000; 28: 3185-90.

10. Ni YN, Luo J, Yu H, et al. Can high-flow nasal cannula reduce the rate of endotracheal intubation in adult patients with acute respiratory failure compared with conventional oxygen therapy and noninvasive positive pressure ventilation? A systematic review and meta-analysis. Chest 2017; 151: 764-75.

11. Huang $H W$, Sun $X M$, Shi $Z H$, et al. Effect of high-flow nasal cannula oxygen therapy versus conventional oxygen therapy and noninvasive ventilation on reintubation rate in adult patients after extubation: a systematic review and meta-analysis of randomized controlled trials. J Intensive Care Med 2018; 33: 609-23.

12. Lee CC, Mankodi D, Shaharyar S, et al. High flow nasal cannula versus conventional oxygen therapy and non-invasive ventilation in adults with acute hypoxemic respiratory failure: a systematic review. Respir Med 2016; 121: 100-8.

13. Maitra S, Som A, Bhattacharjee S, et al. Comparison of high-flow nasal oxygen therapy with conventional oxygen therapy and noninvasive ventilation in adult patients with acute hypoxemic respiratory failure: a meta-analysis and systematic review. J Crit Care 2016; 35: 138-44.

14. Zhao H, Wang H, Sun F, Lyu S, Youzhong A. High-flow nasal cannula oxygen therapy is superior to conventional oxygen therapy but not to noninvasive mechanical ventilation on intubation rate: a systematic review and meta-analysis. Crit Care 2017; DOI: https://doi.org/10.1186/s13054-017-1760-8.

15. Rochwerg B, Granton D, Wang DX, et al. High flow nasal cannula compared with conventional oxygen therapy for acute hypoxemic respiratory failure: a systematic review and metaanalysis. Intensive Care Med 2019; 45: 563-72.

16. Wang $W, X u Y$, Gao $R$, et al. Detection of SARS-CoV-2 in different types of clinical specimens. JAMA 2020; DOI: https:// doi.org/10.1001/jama.2020.3786.

17. World Health Organization. Modes of transmission of virus causing COVID-19: implications for IPC precaution recommendations. Available from URL: https://www.who.int/ news-room/commentaries/detail/modes-of-transmission-of-viruscausing-covid-19-implications-for-ipc-precautionrecommendations (accessed May 2020).

18. Pepper IL, Gerba CP. Chapter 5: Aeromicrobiology. Environ Microbiol. 2015; DOI: https://doi.org/10.1016/b978-0-12394626-3.00005-3.

19. Alhazzani W, Moller MH, Arabi YM, et al. Surviving Sepsis Campaign: The Surviving Sepsis Campaign (SSC) has released guidelines on the management of critically ill adults with coronavirus disease 2019 (COVID-19). Available from URL: https://www.sccm.org/SurvivingSepsisCampaign/Guidelines/ COVID-19 (accessed May 2020).

20. Lamontagne $F$, Angus DC. Toward universal deployable guidelines for the care of patients with COVID-19. JAMA 2020; DOI: https://doi.org/10.1001/jama.2020.5110.

21. Higgins JP, Altman DG, Gotzsche PC, et al. The Cochrane Collaboration's tool for assessing risk of bias in randomised trials. BMJ 2011; DOI: https://doi.org/10.1136/bmj.d5928.

22. Guyatt GH, Oxman AD, Vist GE, et al. GRADE: an emerging consensus on rating quality of evidence and strength of recommendations. BMJ 2008; 336: 924-6.

23. Higgins JP, Thompson SG. Quantifying heterogeneity in a metaanalysis. Stat Med 2002; 21: 1539-58.

24. Morgan RL, Thayer KA, Bero L, et al. GRADE: assessing the quality of evidence in environmental and occupational health. Environ Int 2016; 92-93: 611-6.

25. Bocchile RL, Cazati DC, Timenetsky KT, Serpa Neto A. The effects of high-flow nasal cannula on intubation and re-intubation in critically ill patients: a systematic review, meta-analysis and trial sequential analysis. Rev Bras Ter Intensiva 2018; 30: 48795.

26. Cheng LC, Chang SP, Wang JJ, Hsiao SY, Lai CC, Chao CM. The impact of high-flow nasal cannula on the outcome of immunocompromised patients with acute respiratory failure: a systematic review and meta-analysis. Medicina (Kaunas) 2019; DOI: https://doi.org/10.3390/medicina55100693.

27. Cortegiani A, Crimi C, Sanfilippo $F$, et al. High flow nasal therapy in immunocompromised patients with acute respiratory failure: a systematic review and meta-analysis. J Crit Care 2019; 50: 250-6.

28. Huang CC, Lan HM, Li CJ, et al. Use high-flow nasal cannula for acute respiratory failure patients in the emergency department: a meta-analysis study. Emerg Med Int 2019; DOI: https://doi.org/ $10.1155 / 2019 / 2130935$.

29. Kang H, Zhao Z, Tong Z. Effect of high-flow nasal cannula oxygen therapy in immunocompromised subjects with acute respiratory failure. Respir Care 2020; 65: 369-76.

30. Kheiri B, Zayed $Y$, Barbarawi $M$, et al. High-flow nasal oxygen vs standard oxygen therapy in immunocompromised patients with acute respiratory failure: a meta-analysis of randomized controlled trials. Am J Respir Crit Care Med 2019; 199: A2734 (abstract)

31. Liesching TN, Lei $Y$. Efficacy of high-flow nasal cannula therapy in intensive care units: a meta-analysis of physiological and clinical outcomes. J Intensive Care Med 2019; 34: 140-52.

32. Liu $Q$, Zhu $C$, Lan $C$, Chen $R$. High-flow nasal cannula versus conventional oxygen therapy in patients with dyspnea and 
hypoxemia before hospitalization. Expert Rev Respir Med 2020; 14: 425-33.

33. Ni YN, Luo J, Yu H, Liu D, Liang B, Liang Z. The effect of highflow nasal cannula in reducing the mortality and the rate of endotracheal intubation when used before mechanical ventilation compared with conventional oxygen therapy and non-invasive positive pressure ventilation. a systematic review and metaanalysis. Am J Emerg Med 2018; 36: 226-33.

34. Sklar M, Mohammed A, Orchanian-Cheff A, Del Sorbo L, Mehta $S$, Munshi $L$. The impact of high flow nasal oxygen in the immunocompromised critically ill: a systematic review and metaanalysis. Am J Respir Crit Care Med 2019; 199: A2732 (abstract).

35. Sklar MC, Mohammed A, Orchanian-Cheff A, Del Sorbo L, Mehta $S$, Munshi $L$. The impact of high-flow nasal oxygen in the immunocompromised critically ill: a systematic review and metaanalysis. Respir Care 2018; 63: 1555-66.

36. Tinelli V, Cabrini L, Fominskiy E, et al. High flow nasal cannula oxygen vs. conventional oxygen therapy and non-invasive ventilation in emergency department patients: a systematic review and meta-analysis. J Emerg Med 2019; 57: 322-8.

37. Xu Z, Li Y, Zhou J, et al. High-flow nasal cannula in adults with acute respiratory failure and after extubation: a systematic review and meta-analysis. Respir Res 2018; DOI: https://doi.org/10. 1186/s12931-018-0908-7.

38. Zayed $Y$, Banifadel $M$, Barbarawi $M$, Kheiri B. Non-invasive oxygenation strategies in immunocompromised patients with acute hypoxemic respiratory failure: a pairwise and network meta-analysis of randomized controlled trials. J Intensive Care Med 2019; DOI: https://doi.org/10.1177/0885066619844713.

39. Zayed $Y$, Barbarawi $M$, Kheiri $B$, et al. Initial non-invasive oxygenation strategies in subjects with de novo acute hypoxemic respiratory failure. Respir Care 2019; 64: 1433-44.

40. Wang $Y$, Ni Y, Sun J, Liang Z. Use of high-flow nasal cannula for immunocompromise and acute respiratory failure: a systematic review and meta-analysis. J Emerg Med 2020; 58: 412-23.

41. Geng W, Batu W, You S, Tong Z, He H. High-flow nasal cannula: a promising oxygen therapy for patients with severe bronchial asthma complicated with respiratory failure. Can Respir J 2020; DOI: https://doi.org/10.1155/2020/2301712.

42. Raeisi S, Fakharian A, Ghorbani F, Jamaati H, Sadaat M. Value and safety of high flow oxygenation in the treatment of inpatient asthma: a randomized, double-blind, pilot study. Iran J Allergy Asthma Immunol 2019; 18: 615-23.

43. Ruangsomboon O, Dorongthom T, Chakorn T, et al. High-flow nasal cannula versus conventional oxygen therapy in relieving dyspnea in emergency palliative patients with do-not-intubate status: a randomized crossover study. Ann Emerg Med 2020; 75: 615-26.

44. Makdee O, Monsomboon A, Surabenjawong $U$, et al. High-flow nasal cannula versus conventional oxygen therapy in emergency department patients with cardiogenic pulmonary edema: a randomized controlled trial. Ann Emerg Med 2017; 70(46572): e2.

45. Lemiale V, Mokart D, Mayaux J, et al. The effects of a 2-h trial of high-flow oxygen by nasal cannula versus Venturi mask in immunocompromised patients with hypoxemic acute respiratory failure: a multicenter randomized trial. Crit Care 2015; DOI: https://doi.org/10.1186/s13054-015-1097-0.

46. Azoulay E, Lemiale V, Mokart D, et al. Effect of high-flow nasal oxygen vs standard oxygen on 28-day mortality in immunocompromised patients with acute respiratory failure: the HIGH randomized clinical trial. JAMA 2018; 320: 2099-107.

47. Bell N, Hutchinson CL, Green TC, Rogan E, Bein KJ, Dinh MM. Randomised control trial of humidified high flow nasal cannulae versus standard oxygen in the emergency department. Emerg Med Australas 2015; 27: 537-41.

48. Frat JP, Thille AW, Mercat A, et al. High-flow oxygen through nasal cannula in acute hypoxemic respiratory failure. $\mathrm{N}$ Engl $\mathrm{J}$ Med 2015; 372: 2185-96.

49. Jones $P G$, Kamona $S$, Doran $O$, et al. Randomized controlled trial of humidified high-flow nasal oxygen for acute respiratory distress in the emergency department: the HOT-ER study. Respir Care 2016; 61: 291-9.

50. Parke RL, McGuinness SP, Eccleston $M L$. A preliminary randomized controlled trial to assess effectiveness of nasal high-flow oxygen in intensive care patients. Respir Care 2011; 56: $265-70$.

51. Rittayamai $N$, Tscheikuna J, Praphruetkit $N$, Kijpinyochai S. Use of high-flow nasal cannula for acute dyspnea and hypoxemia in the emergency department. Respir Care 2015; 60: 1377-82.

52. Schwabbauer N, Berg B, Blumenstock G, Haap M, Hetzel J, Riessen $R$. Nasal high-flow oxygen therapy in patients with hypoxic respiratory failure: effect on functional and subjective respiratory parameters compared to conventional oxygen therapy and non-invasive ventilation (NIV). BMC Anesthesiol 2014; DOI: https://doi.org/10.1186/1471-2253-14-66.

53. Hui DS, Chow BK, Lo T, et al. Exhaled air dispersion during high-flow nasal cannula therapy versus CPAP via different masks. Eur Respir J 2019; 53.

54. Loh WN, Tan Y, Taculod J, et al. The impact of high-flow nasal cannula (HFNC) on coughing distance: implications on its use during the novel coronavirus disease outbreak. Can J Anesth 2020; DOI: https://doi.org/10.1007/s12630-020-01634-3.

55. Kotoda M, Hishiyama S, Mitsui K, et al. Assessment of the potential for pathogen dispersal during high-flow nasal therapy. J Hosp Infect 2020; DOI: https://doi.org/10.1016/j.jhin.2019.11. 010.

56. Leung CCH, Joynt GM, Gomersall CD, et al. Comparison of high-flow nasal cannula versus oxygen face mask for environmental bacterial contamination in critically ill pneumonia patients: a randomized controlled crossover trial. J Hosp Infect 2019; 101: 84-7.

57. Leonard $S$, Atwood $C W J r$, Walsh BK, et al. Preliminary findings on control of dispersion of aerosols and droplets during highvelocity nasal insufflation therapy using a simple surgical mask: implications for the high-flow nasal cannula. Chest 2020; DOI: https://doi.org/10.1016/j.chest.2020.03.043.

58. Iwashyna TJ, Boehman A, Capelcelatro J, et al. Variation in aerosol production across oxygen delivery devices in spontaneously breathing human subjects. medRxiv - 2020 . Available from URL: https://www.medrxiv.org/content/10.1101/ 2020.04.15.20066688v1 (accessed May 2020).

59. Roberts $S$, Kabaliuk N, Spence $C$, O'Donnell J, et al. Nasal highflow therapy and dispersion of nasal aerosols in an experimental setting. J Crit Care 2015; 30: 842 (abstract).

60. van Doremalen N, Bushmaker T, Morris DH, et al. Aerosol and surface stability of SARS-CoV-2 as compared with SARS-CoV1. N Engl J Med 2020; DOI: https://doi.org/10.1056/ NEJMc2004973.

61. Bischoff WE, Swett K, Leng I, Peters TR. Exposure to influenza virus aerosols during routine patient care. J Infect Dis 2013; 207: 1037-46.

62. Yang $X, Y u Y, X u J$, et al. Clinical course and outcomes of critically ill patients with SARS-CoV-2 pneumonia in Wuhan, China: a single-centered, retrospective, observational study. Lancet Respir Med 2020; DOI: https://doi.org/10.1016/S22132600(20)30079-5.

63. Fennelly KP, Nardell EA. The relative efficacy of respirators and room ventilation in preventing occupational tuberculosis. Infect Control Hosp Epidemiol 1998; 19: 754-9. 
64. Rochwerg B, Brochard L, Elliott MW, et al. Official ERS/ATS clinical practice guidelines: noninvasive ventilation for acute respiratory failure. Eur Respir J. 2017; 50: 1602426.

65. Yu IT, Xie ZH, Tsoi KK, et al. Why did outbreaks of severe acute respiratory syndrome occur in some hospital wards but not in others? Clin Infect Dis 2007; 44: 1017-25.

66. Fowler RA, Guest CB, Lapinsky SE, et al. Transmission of severe acute respiratory syndrome during intubation and mechanical ventilation. Am J Respir Crit Care Med 2004; 169: 1198-202.
67. Simonds AK, Hanak A, Chatwin M, et al. Evaluation of droplet dispersion during non-invasive ventilation, oxygen therapy, nebuliser treatment and chest physiotherapy in clinical practice: implications for management of pandemic influenza and other airborne infections. Health Technol Assess 2010; 14: 131-72.

Publisher's Note Springer Nature remains neutral with regard to jurisdictional claims in published maps and institutional affiliations. 